\title{
Mobilität, Transport und Erreichbarkeit von Destinationen und Einrichtungen
}

\author{
Coordinating Lead Authors (CLAs) \\ Astrid Gühnemann \\ Lead Authors (LAs) \\ Astrid Gühnemann, Agnes Kurzweil, Wiebke Unbehaun \\ Contributing Authors (CAs) \\ Romain Molitor
}

\subsection{Allgemeine Entwicklung und Trends}

Die verkehrliche Erreichbarkeit von Destinationen und das lokale Angebot an Mobilitätsdiensten können maßgeblich die Attraktivität von Tourismusdestination, jedoch auch die Konkurrenz zwischen ihnen fördern (Prideaux 2000; Rehman Khan et al. 2017; Campa et al. 2018) und beeinflussen die Verkehrsmittelwahl bei An- und Abreise und vor Ort (Herry et al. 1999; Bursa und Mailer 2018). Eine Grundvoraussetzung für eine gute verkehrliche Erreichbarkeit sind hochwertige Verkehrsinfrastrukturen und Verkehrsangebote für die gesamte Reisekette, die zunächst im folgenden Abschnitt für Österreich beschrieben werden, bevor das Mobilitätsverhalten im Tourismus in Österreich aufgezeigt wird. Mobilität bezieht sich in diesem Kapitel auf die An- und Abreise zu und von der Unterkunft sowie auf die Zurücklegung von Wegen vor Ort, um touristische Aktivitäten durchzuführen. Mobilität als Teil touristischer Aktivitäten, z. B. die Nutzung von Bergbahnen bei Wanderungen, Skifahren, ist in anderen Kapiteln enthalten. Derzeit liegen kaum Daten für den vom Tourismus verursachten Güterverkehr vor, daher beziehen sich die Ausführungen im Wesentlichen auf den Personenverkehr.

\subsubsection{Mobilitätsangebote in Österreich und deren Relevanz für den Tourismus}

\section{Infrastrukturanbindungen Straße und Schiene}

Durch Österreich verlaufen vier transeuropäische Verkehrskorridore (TEN-T-Korridore), drei in Nord-Süd-Richtung (baltisch-adriatischer, skandinavisch-mediterraner, Orient/ östlicher Mittelmeerkorridor) sowie der Rhein-Donau-Korridor in West-Ost-Richtung (BMVIT 2014). Durch diese Korridore ist die hochrangige Verbindung (Straße/Schiene/ Wasser) mit den europäischen Herkunftsmärkten gegeben.
Die Gesamtlänge des österreichischen Straßennetzes beträgt ca. $127.500 \mathrm{~km}$, wovon gerundet knapp $2 \%$ auf das hochrangige Straßennetz, $27 \%$ auf Landesstraßen und $72 \%$ auf Gemeindestraßen entfallen (BMVIT 2020). Mit über $1,5 \mathrm{~km}$ Straße pro $\mathrm{km}^{2}$ fällt Österreich damit unter die Länder mit den dichtesten Straßennetzen weltweit (Meijer et al. 2018). Demgegenüber betrug die Gesamtlänge des Schienennetzes (ohne Straßen- und U-Bahnen) 2018 ca. 5650 km (Statistik Austria 2018a), von denen der Großteil als Regional- und Fernverkehrsnetz betrieben wird. Zwischen 1970 und 2011 wurde die Länge des hochrangigen Straßenverkehrsnetzes in Österreich von knapp 450 auf $2185 \mathrm{~km}$ nahezu vervierfacht, während die Länge des Schienennetzes um ca. $13 \%$ abgebaut wurde (Herry et al. 2012).

Entsprechend stellt sich auch die räumliche Verteilung der Qualität von infrastrukturellen Anbindungen dar. Historisch zielt der Ausbau der hochrangigen Infrastruktur in Österreich auf die Verbesserung der Verbindungen zwischen Agglomerationsräumen und größeren Siedlungsgebieten ab, vor allem um Erreichbarkeiten im Pendler-, Berufs- und Güterverkehr zu verbessern (Herry et al. 2012). Aus diesem Grund konzentrieren sich das hochrangige Autobahn- und Schnellstraßennetz und das Schienennetz vor allem auf Gebiete außerhalb von ländlichen Tourismuszentren (Zech et al. 2013). Aufgrund des Reliefs Österreichs sind die Verkehrswege zudem zum großen Teil durch wenige Täler und Pässe gebündelt. Entsprechend kann es gerade in Stoßzeiten des Urlaubsreiseverkehrs entlang der Haupttransitrouten zu starken Kapazitätsengpässen kommen. Nach Angaben des ÖAMTC und Berechnungen der ÖHV liegt der Zeitverlust pro „Reise-Samstag“ auf Österreichs Transitautobahnen bei ca. 1 Mio. Staustunden (zitiert in Mayer-Ertl et al. 2015). Die Raumstruktur Österreichs kann als „Modell der zentralen Peripherie“ beschrieben werden (Lichtenberger 2001), in dem das Zentrum des Landes deutlich schlechtere infrastrukturelle Anbindungen aufweist als die peripheren, grenznahen Gebiete. 


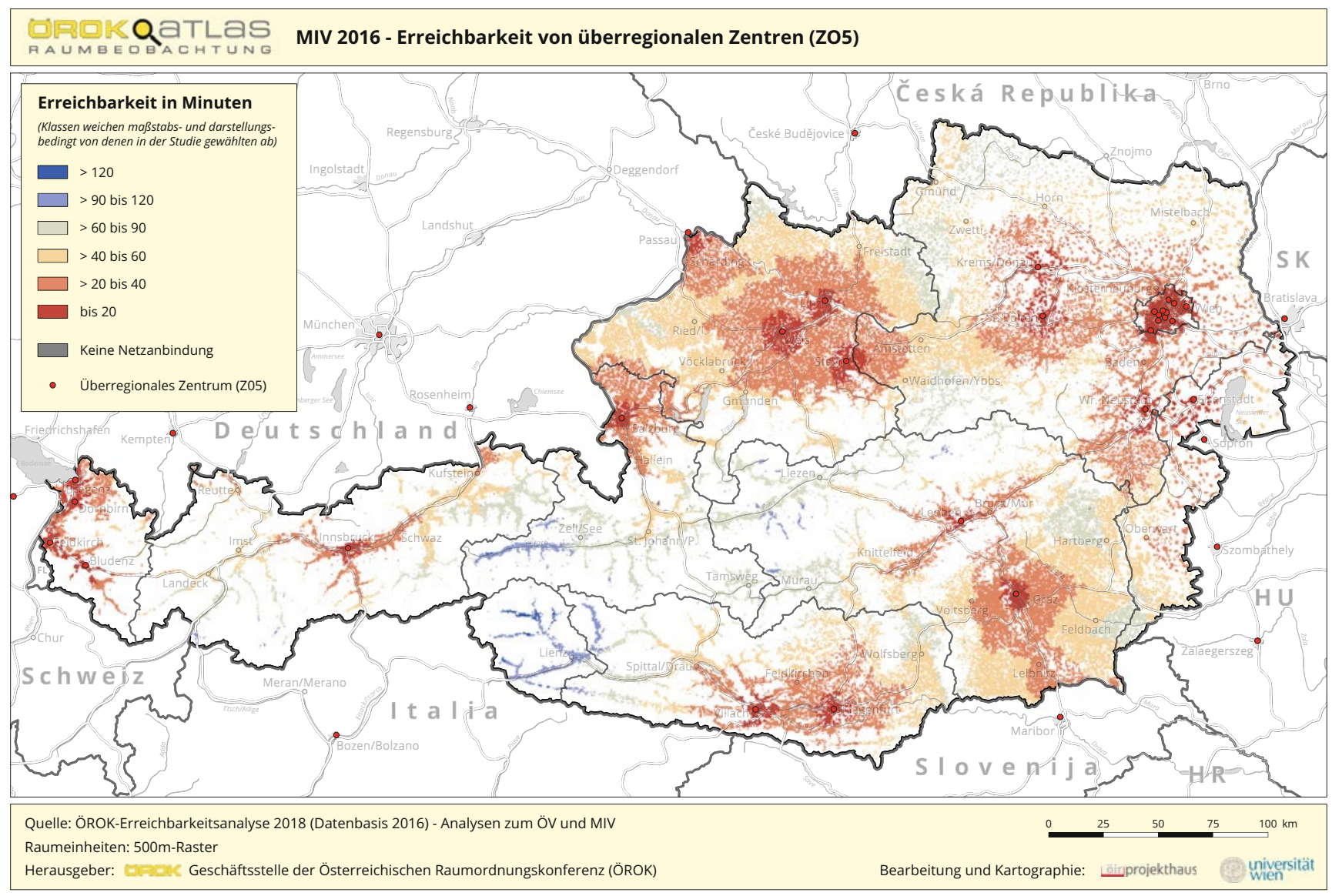

Abb. 3.1 Erreichbarkeiten von überregionalen Zentren mit dem motorisierten Individualverkehr (MIV) 2016 in Österreich (ÖROK 2019). (Quelle: www.oerok-atlas.at, (C2019)

Die infrastrukturelle Anbindung beeinflusst maßgeblich die Reisedauer und Erreichbarkeit von touristischen Destinationen. Abb. 3.1 und 3.2 stellen diese Situation exemplarisch für die Erreichbarkeit von überregionalen Zentren mit dem motorisierten Individualverkehr (MIV) und öffentlichen Verkehr (ÖV) anhand von werktäglichen Reisezeiten dar. Es zeigt sich eine deutlich schlechtere Erschließung gerade in den hochalpinen und touristisch attraktiven Regionen im ÖV (ÖROK 2018), was maßgeblich auch die Mobilität der Touristinnen und Touristen mit öffentlichen Verkehrsmitteln einschränkt, da in diesen Zentren in der Regel auch die Verkehrsknotenpunkte liegen, die für An- und Abreise und oft auch für die Mobilität vor Ort genutzt werden. Diese Situation wirkt sich entsprechend auf die Verkehrsmittelwahl im Tourismus aus, die in Abschn. 3.1.2 dargestellt wird.

Es ist jedoch darauf hinzuweisen, dass im ÖV neben der Reisedauer auch die Bedienhäufigkeit und das Vorhandensein von Direktverbindungen sowohl für überregionale Verbindungen bei An- und Abreise als auch für die Mobilität vor Ort wichtige Komponenten der Erreichbarkeit sind. Zu den Bedienhäufigkeiten im öffentlichen Verkehr in touristischen Gebieten liegen keine flächendeckenden Daten für Österreich vor.
Weiters muss sich eine Verbesserung der Erreichbarkeiten über verbesserte Infrastrukturanbindungen nicht zwangsläufig positiv auf die touristische Entwicklung von Tourismusorten und -regionen auswirken, da es zu einem Verlust an Wertschöpfung durch eine höhere Anzahl an Tagesbesucherinnen und -besuchern kommen kann, die zulasten längerer und wertschöpfungsintensiverer Urlaube gehen kann. Zusätzliche Infrastruktur kann sich sogar negativ auf die Attraktivität von Regionen gerade im naturnahen Tourismus auswirken (Voll 2014).

\section{Verkehrsangebote im öffentlichen Personenverkehr}

Es zeigt sich auch, dass die Stadtregionen Österreichs und die wichtigen regionalen Knotenpunkte über das hochrangige Eisenbahnnetz gut angebunden und so für Touristinnen und Touristen gut erreichbar sind. Auf der Weststrecke betreibt neben der Österreichischen Bundesbahn (ÖBB) auch das private Bahnunternehmen WESTbahn einen regelmäßigen Fernverkehr. Regelmäßige internationale Direktverbindungen mit der Bahn existieren beispielsweise von Tirol nach München, Düsseldorf, Zürich, Bologna, Budapest und Bratislava, die durch Wochenend- und saisonale Fernverkehrs- 


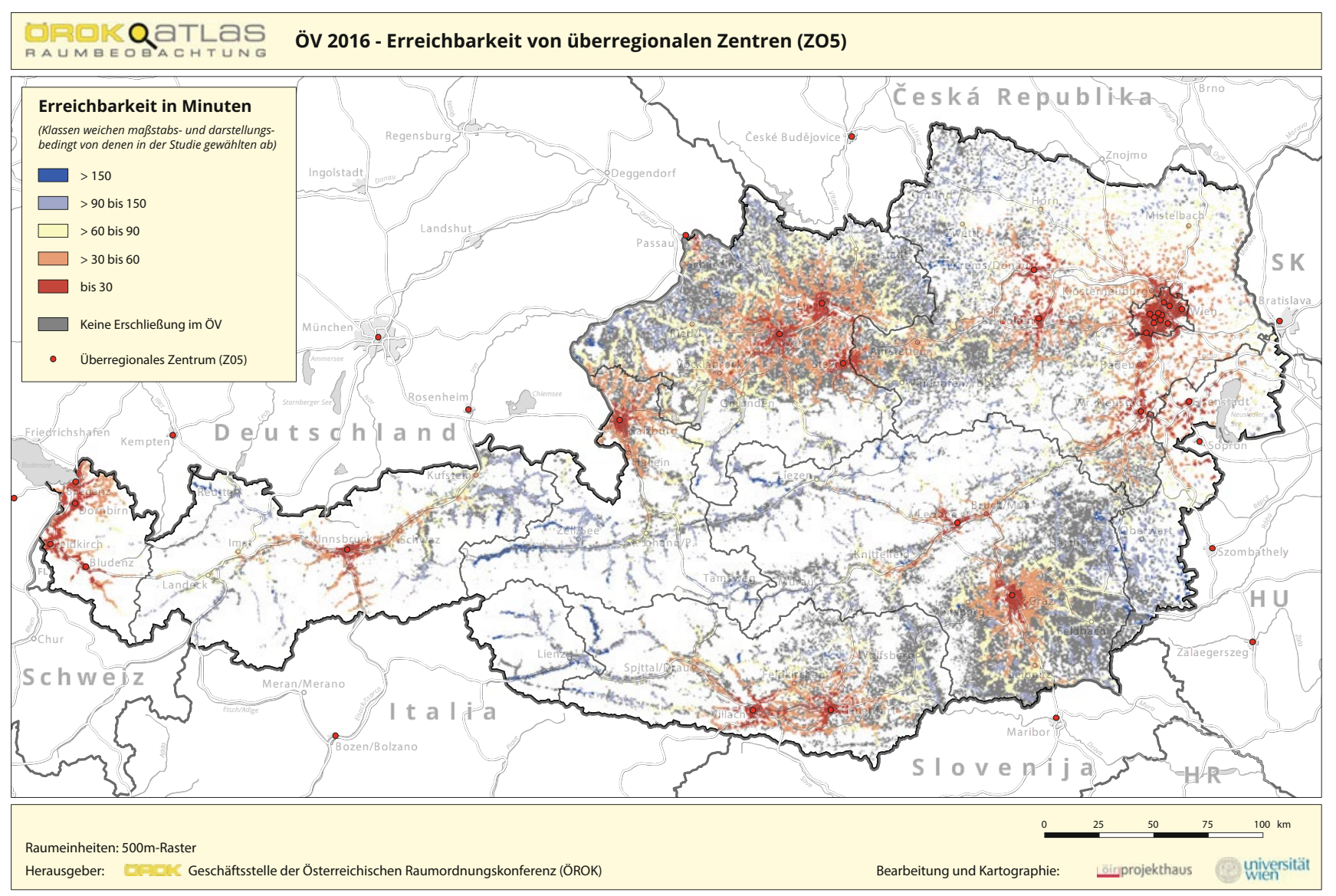

Abb. 3.2 Erreichbarkeiten von überregionalen Zentren mit dem Öffentlichen Verkehr (ÖV) 2016 in Österreich (ÖROK 2019). (Quelle: www. oerok-atlas.at, (C2019)

angebote ergänzt ${ }^{1}$ und sowohl für den Urlaubs- als auch für den Geschäftsreiseverkehr genutzt werden. Für den Tourismus ebenfalls interessant sind die Nachtzugverbindungen, welche die ÖBB in Kooperation mit anderen europäischen Eisenbahnunternehmen anbietet und die Reisen über Nacht mit Schlafgelegenheiten zu Zielen in Österreich, Deutschland, Italien, Schweiz, Slowakei, Kroatien, Slowenien, Polen, Ungarn und Tschechien ermöglichen.

Neben den hochrangigen Bahnverbindungen haben der Omnibusgelegenheitsverkehr und, mit der Liberalisierung im Schienenverkehr und Abbau der Bahnmonopole, auch Linienbusfernverkehre (z. B. über die Kooperation nationaler Busunternehmungen mit Flixbus als Dachmarke) für Urlaubsreisen zunehmende Bedeutung (Bank Austria 2018).

Die Verteilung in die Fläche und zu den Tourismusdestinationen erfolgt über das regionale Bahn- und Busnetz, den öffentlichen Personennah- und -regionalverkehr (ÖPNRV). Im Vergleich mit dem motorisierten Individualverkehr (MIV) ist insbesondere bei der Verteilung in die Fläche der öffentliche Verkehr in Hinblick auf die Reisezeiten deutlich langsamer (Abb. 3.2; ÖROK 2019) oder es sind teilweise keine öffentlichen Verkehrsmittel vorhanden. Eine besondere Herausforderung sind in den Regionen die „erste und letzte Meile“, d. h. die Verbindung von der letzten Haltestelle des öffentlichen Verkehrs zum Ausgangs- bzw. Zielpunkt, und Mobilitätsdienste in den Tourismusdestinationen. Infolge fehlt oft eine vollständige Verkehrsverbindung für An- und Abreise, nämlich für den gesamten Weg inklusive der letzten Meile, und vor Ort zu touristischen Zielen und zur Unterkunft. Die Existenz lückenloser Verkehrsverbindungen zum Zielort bzw. für die Mobilität vor Ort ist eine wesentliche Entscheidungsgrundlage, welches Verkehrsmittel für den Urlaub tatsächlich genutzt wird (Sammer 2013; Peters et al. 2017). Mittlerweile bemühen sich viele Tourismusregionen und -orte, bedarfsorientierte Angebote, wie z. B. Wandertaxis, Skibusse, Rufbussysteme u. Ä., einzurichten, um Lücken in der Erreichbarkeit peripherer Orte und abseits gelegener touristischer Hotspots zu schließen (BMNT und BMVIT 2019; mobyome o.J.). Als erfolgreiche Beispiele sind hier u. a. der Werfenwengshuttle, der Bahnhofsshuttle in Kärnten oder das DefMobil in Osttirol zu nennen (BMNT 2019). 


\section{Saisonale Verteilung Flüge}

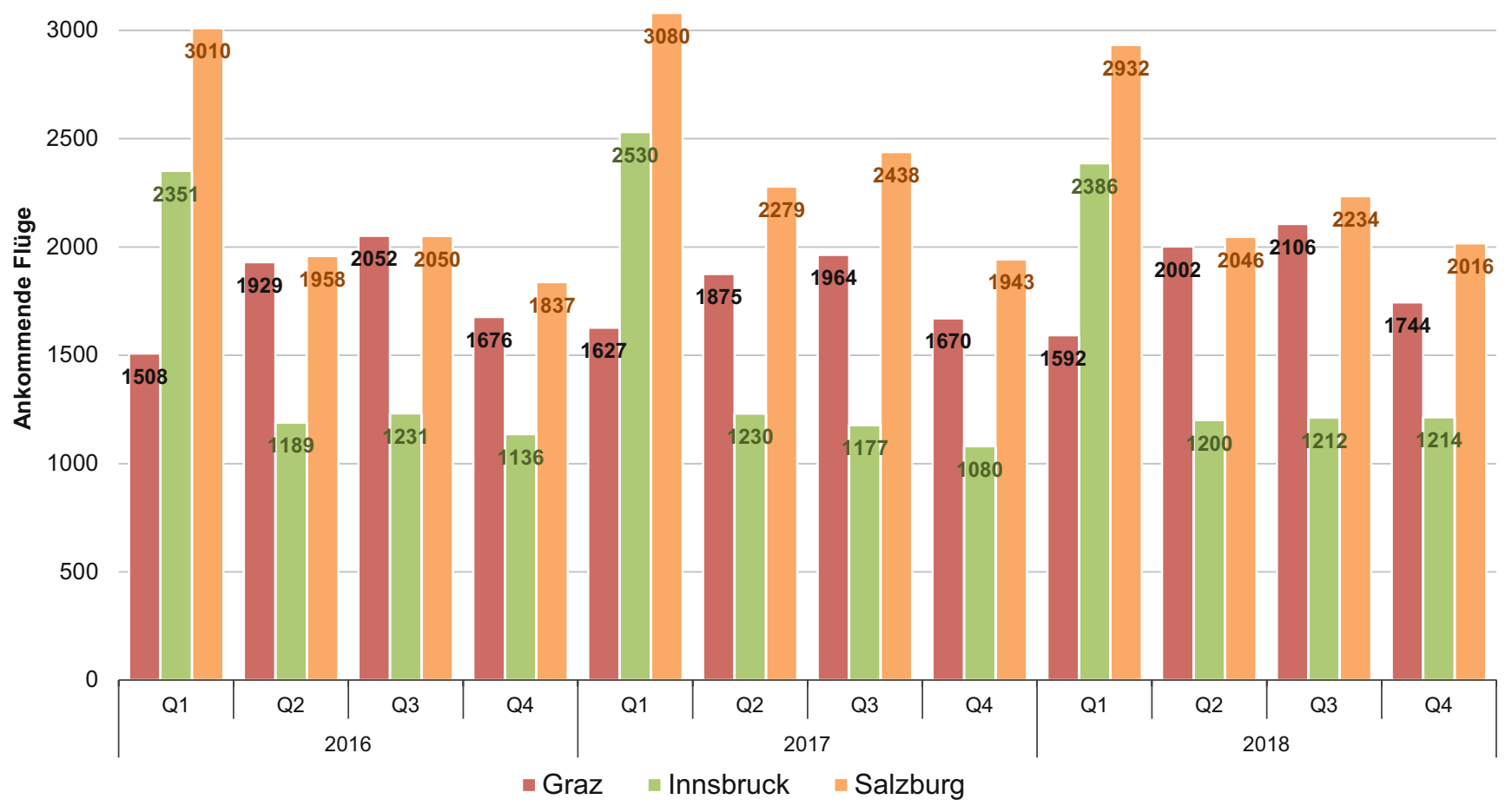

Abb. 3.3 Saisonale Verteilung ausgewählter österreichischer Flughäfen 2016-2018. (Datenquelle: STATcube - Statistische Datenbank von Statistik Austria 2019a; Grafik: Astrid Gühnemann)

\section{Luftverkehr}

Für den österreichischen Tourismus sind neben dem Flughafen Wien-Schwechat zunehmend auch die urlaubsdestinationsnahen Flughäfen Salzburg, Graz, Linz, Klagenfurt und Innsbruck von Bedeutung. Zusätzlich werden ausländische Flughäfen mit guter Anbindung, wie z. B. Memmingen, Bratislava oder München, genutzt. Von Wien-Schwechat wurden im Jahr 2018 ca. 205 Destinationen in 71 Ländern bedient und von 27 Mio. Passagieren genutzt. Die Zahl der Landungen und Abflüge und damit das Angebot an Flügen hat im Zeitraum 2001 bis 2016 um 22 \% zugenommen (Statistik Austria 2018b). Die sitzplatzstärksten Angebote sind auf den Verbindungen zu Zielen in Deutschland sowie den Städten Zürich, Paris, Amsterdam und Istanbul zu finden. Über $85 \%$ der Streckenziele der von Österreich abfliegenden Passagiere liegen innerhalb Europas.

Dabei unterliegen die angebotenen Flugverbindungen saisonalen Unterschieden. So verzeichnen vor allem die Flughäfen Salzburg und Innsbruck die höchsten Flugzahlen im ersten Quartal aufgrund des Wintertourismus, während beispielsweise die Flugbewegungen in Graz aufgrund der höheren Bedeutung des Geschäftsreiseverkehrs einen ausgeglicheneren Verlauf zeigen, wie in Abb. 3.3 dargestellt. Auch unterscheiden sich die angeflogenen Zielflughäfen der
Winter- und Sommerflugpläne. So werden von Salzburg und Innsbruck beispielsweise Direktverbindungen von und nach Großbritannien vorwiegend im Winter angeboten, während im Sommer südliche Ziele im Mittelmeerraum dominieren², was auf eine vorwiegende Nutzung durch einheimische Urlauberinnen und Urlauber hinweist.

Die Anbindung der Flughäfen erfolgt vor allem über das hochranginge Straßennetz und den lokalen ÖV. Wien-Schwechat ist zudem auch im halbstündigen Takt an den Schienenfernverkehr der ÖBB angebunden.

\section{Schifffahrt}

Bedeutendste Wasserstraße in Österreich ist die Donau mit einer Länge von $350 \mathrm{~km}$. Als weitere Wasserstraßen gelten in Österreich der Wiener Donaukanal $(17 \mathrm{~km})$ sowie die Mündungsbereiche der March $(6 \mathrm{~km})$, der Enns $(2,7 \mathrm{~km})$ und der Traun (1,8 km; Herry et al. 2012). Des Weiteren wird auf den österreichischen Seen touristische Linien- und Ausflugsschifffahrt betrieben.

\footnotetext{
2 Siehe https://www.salzburg-airport.com/fluege-anreise/fluege/saisonflugplan/, https://www.innsbruck-airport.com/de/passagiere-besucher/ flugplan.
} 
Abb. 3.4 Verschiedene Reisemuster zwischen Start- und Zieldestination. (Eigene Übersetzung nach Prideaux 2009, S. 104, adaptiert nach Lue et al. 1993, S. 294; Nachdruck aus Lue et al. 1993, mit Genehmigung von Elsevier)
3. Ausflüge zu Zielen von Unterkunft

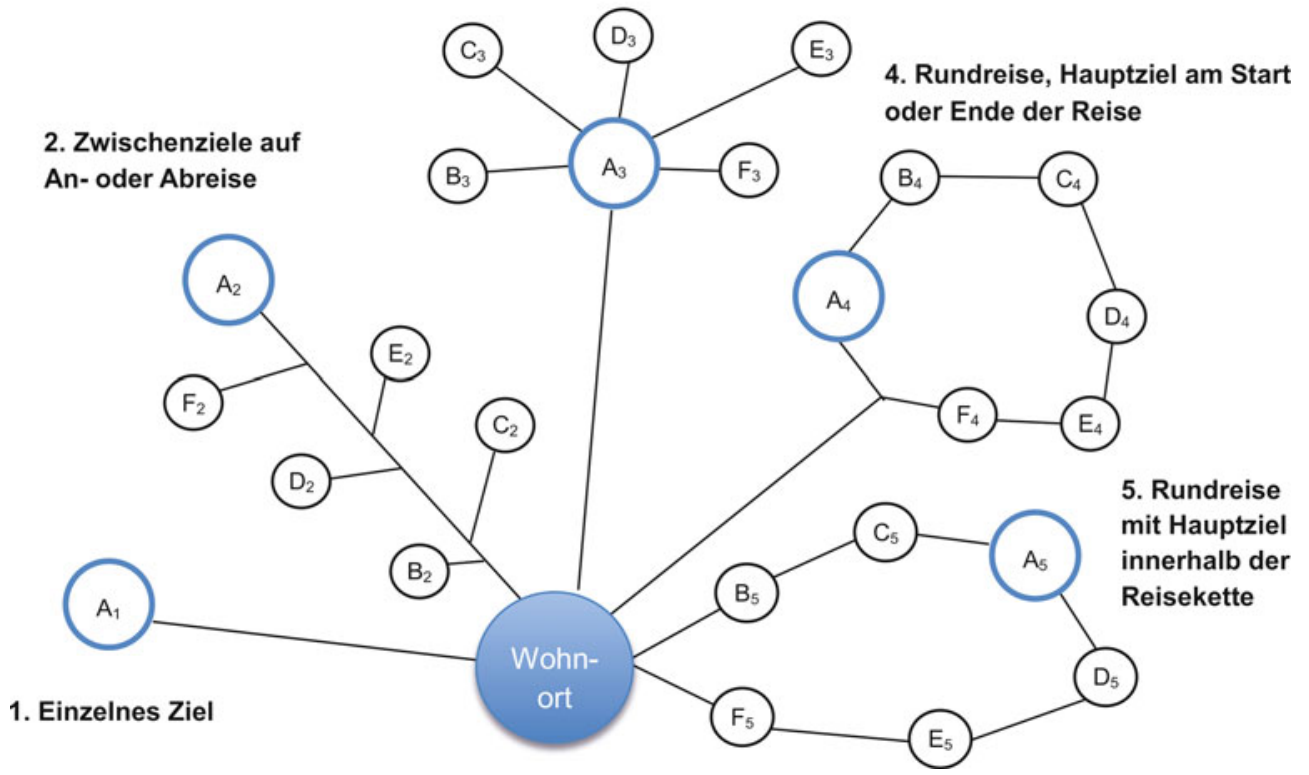

Die Passagierschifffahrt hat in Österreich in erster Linie eine touristische Funktion, einerseits die Linienschiffe für Tagesausflügler, andererseits die Flusskreuzschifffahrt auf der Donau als eigener, wachsender Tourismuszweig. Im Jahr 2018 wurden 465.000 Flusskreuzfahrtpassagiere registriert, eine Steigerung von 3,3\% im Vergleich zum Jahr davor (Viadonau 2019). Innerhalb von 10 Jahren hat sich somit die Passagierzahl der Flusskreuzschifffahrt mehr als verdoppelt, im Jahr 2008 waren auf der Donau rund 198.000 Passagiere unterwegs (Viadonau 2009).

\section{Radverkehrsnetz}

Insgesamt stehen in Österreich rund $14.000 \mathrm{~km}$ Radwegenetz (BMVIT 2013) zur Verfügung. Neben der Alltagsmobilität sind die Radwege ein wichtiger Bestandteil für Freizeitmobilität bzw. Vor-Ort-Mobilität in den Destinationen. Hierzu ist auch das Mountainbikenetz als Teil des Radwegenetzes mit zu betrachten, welches jedoch im Wesentlichen für Freizeitaktivitäten genutzt wird (s. Kap. 7).

Darüber hinaus gibt es nationale und internationale Radrouten, wie z. B. den Donauradweg als wesentliche touristische Produkte mit bspw. bis zu 144.000 Radfahrern pro Jahr in der Wachau oder rund 430.000 Radfahrern östlich von Wien (BMVIT 2013). Insgesamt führen durch Österreich auch 4 Eurovelo-Routen (s. auch Abschn. 7.3.2), das sind internationale Radrouten, die sowohl zur An- und Abreise und Vor-Ort-Mobilität als auch zur Ausübung von touristischen Freizeit- und Urlaubsaktivitäten mit dem Fahrrad genutzt werden. Letztere werden im Kap. 7 näher betrachtet.

\section{Fußgänger- und Wandernetz}

Fußwege und Gehsteige sind ein wesentlicher Bestandteil des Verkehrsnetzes, gleichermaßen für die einheimische Bevöl- kerung, aber auch für Gäste einer Tourismusdestination. Seit den 1960er-Jahren wurden in Ortszentren Fußgängerzonen geschaffen, die u. a. für Aufenthaltsqualität und somit Attraktivität von Städten und touristischen Zentren sorgen (Sabitzer 2011).

Als wichtiger Teil des österreichischen Tourismus kann zudem das Wandernetz angesehen werden. Wie beim Fahrradwegenetz mischt sich vor allem bei Fernwanderwegen die Nutzung zur An- und Abreise mit der touristischen Aktivität, welche im Kap. 7 behandelt wird.

\subsubsection{Tourismusmobilität in Österreich}

\section{Mobilitätsanforderungen von Touristinnen und Touristen}

Für die Mobilität der Touristinnen und Touristen ist die Unterscheidung folgender unterschiedlicher Wege, die die Gäste zu bewältigen haben, notwendig: (a) An- und Abreise und (b) Mobilität vor Ort.

Zudem ist es wichtig, die Muster der touristischen Mobilität (Lew und McKercher 2002; Flognfeldt 2005; Prideaux 2009) zu berücksichtigen (Abb. 3.4):

1) Die An- und Abreise erfolgt direkt zur bzw. von einer einzelnen Zieldestination. Mobilität vor Ort erfolgt ausschließlich innerhalb der Zieldestination (A1). Hierbei unterscheiden sich die Bedürfnisse von Urlaubs- und Geschäftsreisenden, wobei Erstere teilweise spezielle touristische Ziele (Resorts) anfahren, während Letztere eher zu Zentren mit regionalen und administrativen Serviceeinrichtungen reisen.

2) Während der An- oder Abreise zu bzw. von einer Zieldestination (A2) werden mehrere Zwischenziele (B2 bis 
F2) angesteuert. Ziele können dabei, wie auch bei den folgenden Mustern, in mehreren Ländern liegen, beispielsweise eine von Italien startende Reise nach Deutschland mit 2-3 Übernachtungen in Österreich.

3) Die Zieldestination (A3) ist Start- und Zielpunkt für einzelne Ausflüge zu weiteren Destinationen (B3 bis F3).

4) Möglich ist auch, dass es sich bei der gesamten Reise um eine Rundreise entlang mehrerer Zwischenziele (B4 bis F4) ohne festes Endziel handelt, wobei es sich um regionale Touren mit einem Hauptziel am Anfang/Ende (A4) oder

5) Destinationsketten mit aufeinanderfolgenden Zielen mit einem Hauptziel (A5) an einem beliebigen Platz in der Kette (B5 bis F5) handeln kann.

Diese Reisemuster bestimmen maßgeblich die Mobilitätsbedürfnisse bei An- und Abreise und vor Ort sowie den Mobilitätsaufwand (Lew und McKercher 2002; Flognfeldt 2005; Prideaux 2009). Insbesondere für die Kombination von Zielen in Touren und „en route“ (zwischen An- oder Abreise zu bzw. von einer Zieldestination werden mehrere Zwischenziele angesteuert) bietet beispielsweise der Pkw deutliche Flexibilitätsvorteile gegenüber dem öffentlichen Verkehr, sodass sich mit steigender Motorisierung zunehmend Pkworientierte Tourismusformen (Drive-Tourism) etabliert haben (Prideaux 2009).

Zahlreiche weitere Entscheidungskriterien für die Verkehrsmittelwahl im Tourismusverkehr werden in der Literatur aufgeführt (siehe z. B. Verplanken et al. 1994; Herry et al. 1999; Messerli und Trösch 2002; Anable und Gatersleben 2005; Chow et al. 2013; Wallergraber et al. 2014; Juschten et al. 2019). Im Einklang mit der Abgrenzung dieses Berichts werden hier nur die Anforderungen von Übernachtungsgästen beschrieben:

- Erreichbarkeit (Start und Ziel) mit dem jeweiligen Verkehrsmittel, inklusive der Verfügbarkeit von Stellplätzen vor Ort,

- zeitliche Aspekte, wie Reisedauer, verfügbare Abfahrtszeiten und Nutzbarkeit der Reisezeit,

- Kosten für die An- und Abreise und Mobilität vor Ort,

- Bequemlichkeit und Komfort, wie Gepäcktransport, Planungs- und Buchungsaufwand, Umsteigehäufigkeit, Zuverlässigkeit von Anschlüssen und Reisezeiten, besonders wichtig ist eine funktionierende Gepäckzustellung,

- Zuverlässigkeit und Flexibilität,

- Umweltfreundlichkeit und Image des jeweiligen Verkehrsmittels,

- Einstellungen gegenüber verschiedenen Verkehrsmitteln,

- gewohntes Verhalten und persönliche Erfahrungen,

- Umwelteinstellungen als Einflussfaktor für umweltbewusstes Verhalten und klimaschonende Verkehrsmittelwahl,
- Attraktivität und Komfort der Reise, wie die Schönheit der Landschaft und die Qualität bzw. der Komfort des Reiseverkehrsmittels - die Reise als eigenes Erlebnis, dadurch kann die Nutzung klimaschonender Verkehrsmittel gesteigert werden, auch wenn der Zeit- und Kostenvorteil des Pkws weiterhin besteht,

- Informiertheit über bestehende Mobilitätsangebote,

- Einfachheit der Buchung,

- Reisebegleitung (Einzelreisende, Reisende mit Partnern, Familien oder Freunden),

- Pkw-Besitz.

\section{Mobilitätsverhalten von Touristinnen und Touristen in Österreich}

Die zurückgelegte Entfernung sowie die Wahl des Verkehrsmittels und die daraus resultierenden Verkehrsmengen je Verkehrsmittel haben einen wesentlichen Einfluss auf die Umweltund Klimaverträglichkeit der Mobilität. Für Nächtigungsgäste in Österreich wird jährlich im Rahmen von Urlauberbefragungen $^{3}$ die Verkehrsmittelwahl für die An- und Abreise in den Urlaub erhoben, siehe Tab. 3.1. Demnach nutzen sowohl für den Winter- als auch den Sommerurlaub rund drei Viertel der Gäste den Pkw. Rund $10 \%$ der Gäste reisten mit dem Flugzeug und $8 \%$ mit der Bahn an, wobei im Winter der Anteil für das Flugzeug mit rund $13 \%$ deutlich höher ausfällt, während im Sommer die Bahn stärker genutzt wird. Der Anteil von rund $75 \%$ zeigt die Bedeutung des eigenen Pkws. Das Flugzeug gewinnt aufgrund der Zunahme weiter entfernter Herkunftsmärkte an Bedeutung und hat mittlerweile als das am zweithäufigsten genutzte Verkehrsmittel für An- und Abreise die Bahn anteilsmäßig überholt (Österreich Werbung 2019).

Ein anderes Bild zeigt die Urlauberbefragung für das Reiseverhalten der Österreicherinnen und Österreicher im Inland. Demnach nutzen rund $83 \%$ von ihnen für einen Inlandsurlaub den eigenen Pkw und rund $10 \%$ den Zug (Österreich Werbung 2019). Die Tourismusstatistik der Statistik Austria zeigt für Urlaubsreisen von Österreicherinnen und Österreichern im Inland ein etwas anderes Bild: Demnach nutzten im Jahr 2018 rund 15,3\% die Bahn, rund 78,5\% den Pkw bzw. rund 0,2 \% das Flugzeug (Statistik Austria 2019d).

Innerhalb von Österreich und je nach Urlaubsart sowie Verfügbarkeit von Bahninfrastruktur variiert die Verkehrsmittelwahl markant. Die Zieldestinationen im Naturtourismus liegen zumeist in peripheren Gebieten, wie z. B. in Teilen der Alpen, die i. d. R. leichter mit dem Pkw als mit öffentlichen Verkehrsmitteln zu erreichen sind. Für die Anreise wird demgemäß überdurchschnittlich häufig der Pkw mit einem Anteil von rund $87 \%$ gewählt, rund $5 \%$ reisen mit dem Zug an, $3 \%$ mit dem Flugzeug (Österreich Werbung 2019).

\footnotetext{
${ }^{3}$ Im Zuge dieser Onlinebefragungen werden Tagesgäste und (ausschließlich) Geschäftsreisende zu Beginn der Befragung miterfasst, dann aber nicht weiter befragt (Österreich Werbung 2019).
} 
Tab. 3.1 Verkehrsmittelwahl bei der An-/Abreise von Gästen in Österreich laut T-Mona-Urlauberbefragung 2017/2018. (Österreich Werbung 2019)

\begin{tabular}{|c|c|c|c|c|c|c|c|c|c|}
\hline & \multicolumn{3}{|c|}{ Gäste in Österreich gesamt } & \multicolumn{3}{|c|}{ Aus Österreich } & \multicolumn{3}{|c|}{ Aus dem Ausland } \\
\hline & $\begin{array}{l}\text { Winter } \\
2017 / 2018 \\
{[\%]}\end{array}$ & $\begin{array}{l}\text { Sommer } \\
2018[\%]\end{array}$ & $\begin{array}{l}\text { Gesamt } \\
{[\%]}\end{array}$ & $\begin{array}{l}\text { Winter } \\
2017 / 2018 \\
{[\%]}\end{array}$ & $\begin{array}{l}\text { Sommer } \\
2018[\%]\end{array}$ & $\begin{array}{l}\text { Gesamt } \\
{[\%]}\end{array}$ & $\begin{array}{l}\text { Winter } \\
2017 / 2018 \\
{[\%]}\end{array}$ & $\begin{array}{l}\text { Sommer } \\
2018[\%]\end{array}$ & $\begin{array}{l}\text { Gesamt } \\
{[\%]}\end{array}$ \\
\hline Auto & 76,0 & 75,0 & 75,3 & 81,2 & 83,5 & 83,3 & 75,8 & 73,6 & 73,6 \\
\hline Motorrad & 0,0 & 1,0 & 0,7 & 0,3 & 0,6 & 0,6 & 0,0 & 1,1 & 0,7 \\
\hline $\begin{array}{l}\text { Wohnwa- } \\
\text { gen/Wohn- } \\
\text { mobil }\end{array}$ & 1,0 & 3,0 & 2,4 & 0,7 & 2,2 & 2,0 & 1,0 & 3,1 & 2,5 \\
\hline Bahn & 7,0 & 9,0 & 8,4 & 10,3 & 10,1 & 10,2 & 6,9 & 8,8 & 8,2 \\
\hline $\begin{array}{l}\text { Organi- } \\
\text { sierter } \\
\text { Reisebus }\end{array}$ & 2,0 & 1,0 & 1,3 & 0,2 & 0,6 & 0,5 & 2,1 & 1,1 & 1,4 \\
\hline $\begin{array}{l}\text { Fernbus/ } \\
\text { Linienbus }\end{array}$ & 1,0 & 2,0 & 1,7 & 2,1 & 0,8 & 0,9 & 1,0 & 2,2 & 1,8 \\
\hline Flugzeug & 13,0 & 9,0 & 10,1 & 5,1 & 1,8 & 2,1 & 13,3 & 10,2 & 11,1 \\
\hline Anderes & 0,0 & 1,0 & 0,7 & 0,0 & 0,4 & 0,4 & 0,0 & 1,1 & 0,8 \\
\hline
\end{tabular}

Im Gegenzug ergibt sich in Städten die Chance, aufgrund ihres besseren ÖV-Angebotes und höherer Attraktivität aktiver Mobilität sowie aufgrund kürzerer Wege und besserer Infrastrukturausstattung, nachhaltige Verkehrsmittel für die Vor-Ort-Mobilität attraktiv zu machen. Im Städtetourismus ist das Flugzeug mit einem Anteil von $36 \%$ das am häufigsten gewählte Verkehrsmittel für die An- und Abreise, der Pkw wird dafür zu $33 \%$ genutzt. Die Bahn ist mit einem Anteil von $25 \%$ das am dritthäufigsten genutzte Verkehrsmittel und liegt somit ebenso wie die zuvor genannten Verkehrsmittel über dem Österreich-Durchschnitt (Österreich Werbung 2019).

Daten, die eine Ableitung der tourismusbedingten Verkehrsleistung in Österreich erlauben und damit in weiterer Folge den Anteil an den verkehrsbedingten Treibhausgasemissionen aus dem Tourismus abschätzen ließen, stehen auf nationaler Ebene in unzureichendem Maß zur Verfügung. Potenzielle Quellen sind die auf Mobilitätsbefragungen basierenden Verkehrsstatistiken des BMVIT, die Aussagen über den Verkehrszweck für Wege der in Österreich ansässigen Bevölkerung enthalten (Herry et al. 2012; Follmer et al. 2016), sowie Tourismusstatistiken, die Aussagen über die Ankünfte einerseits und die Verkehrsmittelwahl andererseits enthalten (Österreich Werbung 2019; Statistik Austria 2019d). Eine Abschätzung der Verkehrsleistung unter Berücksichtigung von Verkehrsmittelwahl und durchschnittlicher Entfernung der Zielmärkte sowie daraus resultierender Treibhausgasemissionen, die von Österreicherinnen und Österreichern verursacht werden, ist Abschn. 11.2 zu entnehmen bzw. Treibhausgasemissionen, die der Tourismus nach Österreich erzeugt, dem Abschn. 11.3.

\section{Unterschiedliches Mobilitätsverhalten nach Herkunftsländern}

Unterschiedlich ist auch das Anreiseverhalten der Gäste aus den unterschiedlichen Herkunftsländern. Dieses ist in erster Linie abhängig von der Distanz zur Urlaubsdestination. Erwartungsgemäß nimmt der Anteil des Flugzeuges mit der Entfernung zu. Besonders Gäste aus den Hauptmärkten Deutschland und den Beneluxstaaten wählen überwiegend den eigenen Pkw. Der Anteil der Bahnreisenden ist entsprechend der T-Mona-Befragung im Sommer höher als im Winter (Österreich Werbung 2019). Dieser Unterschied kann auf eine höhere Bedeutung des Gepäcktransports als Hinderungsgrund für eine Anreise mit der Bahn im Winter zurückgeführt werden. Allerdings sind auch für Wintergäste weitere vielfältige Gründe (wie Kosten, Komfort, Verfügbarkeit und subjektive Disponiertheit) für die Wahl des Verkehrsmittels relevant (Herry et al. 1999; Wallergraber et al. 2014).

Grundsätzlich lässt sich feststellen, dass die Datenlage zur Entwicklung der Tourismusmobilität unzureichend ist, da keine vollständigen Zeitreihen oder vergleichbaren Daten für alle österreichischen Bundesländer vorliegen und insbesondere aktuelle Informationen zu den Hintergründen der touristischen Mobilität, wie beispielsweise die Motive für die Verkehrsmittelwahl und die Wegezwecke, österreichweit kaum vorhanden sind. Hier besteht erheblicher Datenbedarf.

\section{Mobilität von Beschäftigten im Tourismus}

Neben dem Verkehr, der durch die Gäste selbst entsteht, sind auch der Berufsverkehr des Personals, der tourismusbezogene Personenwirtschaftsverkehr sowie der Alltagsverkehr 
der Beschäftigten im Tourismus mit anzurechnen. In einer Fallstudie für Alpbach in Tirol berechnen Mailer et al. (2019) auf Basis von Befragungsdaten zum Mobilitätsverhalten, dass die von Beschäftigten zurückgelegte Jahresdistanz weniger als $1 \%$ derer von Gästen beträgt und der überwiegende Teil dieser Verkehrsleistung von Beschäftigten als Tagespendler mit dem Pkw zur Arbeitsstätte zurückgelegt wird. Fahrten von Saisonkräften in die Heimatgemeinden werden vor allem vor und nach der Saison durchgeführt und fallen so kaum ins Gewicht. Es liegen jedoch keine Daten vor, die eine Abschätzung der Verkehrsleistung durch im Tourismus Beschäftigte für Gesamt-Österreich zulassen.

\section{Güterverkehr für den Tourismus}

Getrieben durch wirtschaftliches Wachstum bei gleichzeitig steigender internationaler Verflechtung und modernen, auf flexiblen und ,just in time“ ausgerichteten Logistikkonzepten nahm der gesamte Güterverkehr in Österreich im Zeitraum von 1990 bis 2016 um mehr als $130 \%$ von etwas über 30 Mrd. Tonnen-km auf über 70 Mrd. Tonnen-km zu (Sammer et al. 2009; Umweltbundesamt 2018a). Dabei beträgt der Anteil der auf der Bahn zurückgelegten Güterverkehrsleistung rund $29 \%$, was neben marktstrukturellen Ursachen auch auf eine fehlende Kostenwahrheit im Verkehr und teilweise ineffiziente Abwicklung internationaler Bahnverkehre zurückzuführen ist (Umweltbundesamt 2016). Gleichzeitig stieg auch der Konsum von tourismusverwandten und nichttourismusspezifischen Waren und Dienstleistungen in Österreich inklusive wertvoller Waren zwischen 2000 und 2017 um ca. $70 \%$ auf knapp 7,5 Mrd. $€$ (Statistik Austria 2019b). Dieses Wachstum beeinflusst aller Wahrscheinlichkeit nach vor allem den Transport auf der Straße, da die zur Versorgung des Tourismus notwendigen Güter, wie z. B. Nahrungsmittel oder hochwertige Einkaufswaren sowie Abfälle, hochgradig straßentransportaffin sind, insbesondere bei der $\mathrm{Zu}$ - und $\mathrm{Ab}$ lieferung in ländlichen Räumen (Herry und Sedlacek 2014). Es ist daher davon auszugehen, dass mit steigender Nachfrage im Tourismus auch die damit verbundenen Güterverkehrsleistungen vor allem im Straßenverkehr entsprechend ansteigen. Derzeit liegen jedoch keine spezifischen Daten für den vom Tourismus verursachten Güterverkehr für Österreich vor. Hier besteht Forschungsbedarf.

\subsection{Klimarelevante Entwicklungen im Tourismusverkehr}

\subsubsection{Verändertes Reiseverhalten}

Während Gäste in Österreich in den 1970er-Jahren im Schnitt noch knapp 7 Nächte (bei Gästen aus dem Ausland) bzw. 6 Nächte (bei Gästen aus dem Inland) in einer Unterkunft verbrachten, haben sich diese auf heute knapp 3,5 bzw. 3,0 Übernachtungen verkürzt (BMNT 2019), wodurch die Anzahl der An- und Abreisen bei steigendem Nächtigungsvolumen überproportional steigt und es zu einer stärkeren Überlagerung des An- und Abreiseverkehrs mit dem werktäglichen Alltagsverkehr kommt. Beispielsweise stieg die Anzahl der Übernachtungen in Tirol zwischen 2000 und 2019 um ca. $6 \%$, während gleichzeitig die Anzahl der Ankünfte um $21 \%$ wuchs (Bursa 2019). Zusätzlich kommt es zu einer verstärkten Individualisierung der Reisen gerade bei Kurzurlauben und dadurch steigenden Erwartungen der Gäste bezüglich der Anzahl und Vielfalt der zu besuchenden Sehenswürdigkeiten (Zech et al. 2013; Peters et al. 2017). Daraus folgt, dass die Anforderungen der Reisenden an die Flexibilität und Geschwindigkeit der verfügbaren Verkehrsmittel stark gestiegen sind, um die Zeit für die An- und Abreise möglichst kurz zu halten und maximal viel Zeit vor Ort zur Verfügung zu haben. Dies begünstigt den privaten Pkw in der Verkehrsmittelwahl und stellt Destinationen, die auf eine klimaschonende Anreise setzen, vor große Herausforderungen (Gronau und Kagermeier 2007).

\subsubsection{Alternde Bevölkerung}

Die Alterung der Bevölkerung stellt auch die Tourismusmobilität vor allem dann vor Herausforderungen, wenn man daraus resultierende Potenziale gut ausschöpfen möchte. Bedingt durch eine steigende Anzahl an gesunden älteren Personen sowie die steigende Lebenserwartung ist diese touristische Zielgruppe zunehmend mobil im Alter, was zu einer steten Ausweitung des Freizeitverkehrs in dieser Bevölkerungsgruppe führt (Götz et al. 2002). Diese stark wachsende Bevölkerungsgruppe zeichnet sich durch einen besonders hohen Motorisierungsgrad bzw. Anteil mit Führerscheinbesitz aus, ist stark Pkw-affin und zudem von den Vorteilen alternativer Verkehrsmodi weniger überzeugt (Kasper und Scheiner 2003; Zmud et al. 2017). Daher stellt sie eine besonders große Herausforderung beim Umstieg auf klimaschonende Mobilitätsformen dar. Dies gilt umso mehr, als für diese Gruppe aktuell noch nicht von einer großen Technologieaffinität und Erfahrung im Umgang mit Smartphones und dem dadurch ermöglichten Zugang zu digitalen, multimodalen Informationsund Buchungssystemen ausgegangen werden kann (Zmud et al. 2017). Dementsprechend vielfältig sollten auch die genutzten Kommunikationskanäle ausgewählt werden, um ältere Touristinnen und Touristen auf bestehende klimaschonende Mobilitätsangebote aufmerksam zu machen (Segert 2012; Landesrecht Oberösterreich 2013). 
Tab. 3.2 Verkehrsmittelwahl bei der Anreise nach Herkunftsländern für Winter und Sommer nach T-Mona-Urlauberbefragung $2017 / 2018$. (Österreich Werbung 2019)

\begin{tabular}{|c|c|c|c|c|c|c|c|c|c|}
\hline $\begin{array}{l}\text { Herkunfts- } \\
\text { land }\end{array}$ & $\begin{array}{l}\text { Saison } \\
\text { Winter } \\
\text { Som- } \\
\text { mer }\end{array}$ & Auto $[\%]$ & $\begin{array}{l}\text { Motorrad } \\
{[\%]}\end{array}$ & $\begin{array}{l}\text { Wohn- } \\
\text { wagen/ } \\
\text { Wohn- } \\
\text { mobil [\%] }\end{array}$ & Bahn [\%] & $\begin{array}{l}\text { Organi- } \\
\text { sierter } \\
\text { Reisebus } \\
{[\%]}\end{array}$ & $\begin{array}{l}\text { Fernbus/ } \\
\text { Linienbus } \\
{[\%]}\end{array}$ & $\begin{array}{l}\text { Flugzeug } \\
{[\%]}\end{array}$ & $\begin{array}{l}\text { Anderes } \\
{[\%]}\end{array}$ \\
\hline \multirow[t]{2}{*}{ Österreich } & $\mathrm{W}$ & 81 & 0 & 1 & 10 & 0 & 2 & 5 & 0 \\
\hline & S & 83 & 1 & 2 & 10 & 1 & 1 & 2 & 0 \\
\hline \multirow[t]{2}{*}{ Belgien } & W & 79 & 0 & 0 & 1 & 12 & 1 & 8 & 0 \\
\hline & S & 87 & 1 & 2 & 2 & 1 & 0 & 7 & 1 \\
\hline \multirow[t]{2}{*}{ Deutschland } & W & 85 & 0 & 1 & 7 & 2 & 1 & 4 & 0 \\
\hline & S & 83 & 1 & 3 & 7 & 1 & 1 & 4 & 1 \\
\hline \multirow[t]{2}{*}{ Frankreich } & W & \multicolumn{8}{|c|}{ nicht vorliegend } \\
\hline & S & 58 & 1 & 3 & 5 & 3 & 2 & 29 & 0 \\
\hline \multirow[t]{2}{*}{ Italien } & W & \multicolumn{8}{|c|}{ nicht vorliegend } \\
\hline & S & 74 & 1 & 4 & 5 & 1 & 2 & 13 & 0 \\
\hline \multirow[t]{2}{*}{ Niederlande } & W & 91 & 0 & 1 & 1 & 2 & 0 & 4 & 0 \\
\hline & S & 85 & 0 & 6 & 3 & 1 & 0 & 3 & 0 \\
\hline \multirow[t]{2}{*}{ Russland } & W & 34 & 0 & 0 & 13 & 6 & 3 & 45 & 0 \\
\hline & S & 18 & 0 & 0 & 18 & 1 & 4 & 57 & 1 \\
\hline \multirow[t]{2}{*}{ Schweiz } & W & \multicolumn{8}{|c|}{ nicht vorliegend } \\
\hline & $\mathrm{S}$ & 74 & 1 & 4 & 9 & 1 & 2 & 7 & 1 \\
\hline \multirow{2}{*}{$\begin{array}{l}\text { Tschechische } \\
\text { Republik }\end{array}$} & W & 92 & 0 & 0 & 3 & 3 & 1 & 0 & 0 \\
\hline & $\mathrm{S}$ & 84 & 1 & 2 & 6 & 3 & 4 & 0 & 0 \\
\hline \multirow[t]{2}{*}{ Ungarn } & W & \multicolumn{8}{|c|}{ nicht vorliegend } \\
\hline & $\mathrm{S}$ & 83 & 0 & 1 & 11 & 3 & 1 & 0 & 0 \\
\hline \multirow{2}{*}{$\begin{array}{l}\text { Vereinigte } \\
\text { Staaten von } \\
\text { Amerika }\end{array}$} & W & \multicolumn{8}{|c|}{ nicht vorliegend } \\
\hline & $\mathrm{S}$ & 15 & 0 & 0 & 28 & 2 & 5 & 45 & 4 \\
\hline \multirow{2}{*}{$\begin{array}{l}\text { Vereinigtes } \\
\text { Königreich }\end{array}$} & W & 13 & 0 & 0 & 4 & 8 & 3 & 71 & 1 \\
\hline & S & 16 & 0 & 2 & 7 & 4 & 0 & 70 & 2 \\
\hline $\begin{array}{l}\text { Anmerkung: } \\
\text { Flugzeug aus } \\
\text { besuchen, das } \\
\text { anderen Verke }\end{array}$ & $\begin{array}{l}1 \text { der H } \\
\text { Verein } \\
\text { ißt, sie } 1\end{array}$ & $\begin{array}{l}\text { Inftsländer } \\
\text { n Staaten c } \\
\text { men zuers } \\
\text { Österreicl }\end{array}$ & $\begin{array}{l}\text { bhängig von } \\
\text { fte damit zu } \\
\text { nit dem Flug } \\
\text { veiter }\end{array}$ & $\begin{array}{l}\text { atenverfügb } \\
\text { mmenhänge } \\
\text { eug in einem }\end{array}$ & $\begin{array}{l}\text { keit. Der u } \\
\text { dass viele } \\
\text { nderen Lai }\end{array}$ & $\begin{array}{l}\text { vartet ni } \\
\text { ereuropa } \\
\text { und rei }\end{array}$ & $\begin{array}{l}\text { e Anteil de } \\
\text { dann im Ve }\end{array}$ & $\begin{array}{l}\text { Anreise mit } \\
\text { ere Länder } \\
\text { uf der Reis }\end{array}$ & $\begin{array}{l}\text { Europa } \\
\text { Eut einem }\end{array}$ \\
\hline
\end{tabular}

\subsubsection{Wandel der Herkunftsmärkte}

Der wichtigste Herkunftsmarkt für ausländische Gäste Österreichs ist Deutschland (s. Abschn. 1.2). Das meist gewählte Verkehrsmittel der deutschen Österreichgäste und auch der übrigen europäischen Gäste ist der private Pkw (s. Tab. 3.2). Aber gerade im Winterhalbjahr werden zusätzliche Flugverbindungen von skigebietsnahen Flughäfen wie Innsbruck, Salzburg und Klagenfurt in europäische Großstädte eingerichtet und beworben (s. z. B. Salzburg Airport 2019), welche zu einer weiteren Steigerung des Flugverkehrs beitragen können.

Bei der Anreise mit dem Flugzeug ist das Vereinigte Königreich von Großbritannien und Nordirland (kurz: Vereinigtes Königreich) einer der größten Wachstumsmärkte in den vergangenen Jahren (Statistik Austria 2018b). Bei einem EUAustritt des Vereinigten Königreichs können Veränderungen bei Start- und Landerechten, bei rechtlichen Rahmenbedingungen (z. B. Gültigkeit von Führerscheinen, Visabestimmungen) oder bei der wirtschaftlichen Kaufkraft von Reisenden 
Auswirkungen auf diesen Markt und auf die Mobilität bei Anund Abreise sowie vor Ort besitzen. Diese sind zum jetzigen Zeitpunkt aufgrund der ungeklärten Modalitäten zukünftiger Kooperation zwischen der EU und dem Vereinigten Königreich jedoch nicht bestimmbar (Jamnig 2019).

Außerhalb Europas werden zunehmend ferne Märkte beworben, insbesondere im asiatischen Raum und Russland. Daher ist eine starke Zunahme der mit dem Flugzeug anreisenden Gäste und der damit verbundenen Treibhausgasemissionen zu erwarten (Zech et al. 2013; Peters et al. 2017).

\subsubsection{Entwicklung des Führerschein- und Pkw-Besitzes}

Einen positiven Impuls für die Wahl alternativer, klimaschonender Verkehrsmittel in der Reisemobilität könnte der abnehmende Pkw-Besitz in den europäischen Großstädten mit sich bringen. Es ist zu beobachten, dass der Führerscheinbesitz von jungen Erwachsenen, beispielsweise in Deutschland und dem Vereinigten Königreich, abnimmt (STRATA et al. 2013). Auch der Anteil der Haushalte ohne eigenen Pkw ist in den vergangenen Jahren in vielen Großstädten Europas gestiegen. Dieser wuchs beispielsweise zwischen 2009/2010 und 2014/2015 in Wien von 41 auf $45 \%$, während er landesweit weitgehend konstant bei $23 \%$ lag (Statistik Austria 2011, 2016). Ähnliche Entwicklungen werden auch aus anderen großen Städten Europas gemeldet. So zeigen die Zahlen des Schweizer Mikrozensus für Zürich, dass der Anteil der autofreien Haushalte von $42,2 \%$ in 2000 auf 52,8 \% in 2015 gestiegen ist (BFS und ARE 2017). Gut ein Viertel dieser Haushalte ist als bewusst autofrei zu bezeichnen (Haefeli und Arnold 2016). In Berlin lag der Anteil der Haushalte ohne Pkw bereits 2008 bei $45 \%$ (Ahrens et al. 2016), in London in 2014 bei knapp $40 \%$ (ONS 2016). Autofreie Haushalte nutzen häufig Carsharing oder Mietwagenangebote für Freizeit- und Tourismusaktivitäten, die mit öffentlichen Verkehrsmitteln schlecht erreichbar sind, d. h., Pkw-Besitz und Pkw-Nutzung sind zunehmend entkoppelt. Zudem deuten Daten darauf hin, dass autofreie Haushalte offener für klimaschonende Mobilitätsangebote sind und somit ein größerer Bedarf an diesen zu und in den Tourismusdestinationen zu erwarten ist (Juschten et al. 2019).

In Österreich liegen die Zahlen für den Pkw-Besitz und die Neuzulassungen nach wie vor auf einem hohen Niveau. Von 1995 bis 2014 nahm die Pkw-Verfügbarkeit in Österreich durchschnittlich von ca. einem auf 1,24 Pkws pro Haushalt zu (Follmer et al. 2016), der gesamte Pkw-Bestand Österreichs stieg zwischen 2002 und 2018 um $40 \%$ auf knapp 5 Mio. Pkw (Statistik Austria 2019c). Auch in den meisten anderen europäischen Ländern ist in der Summe eine Trendumkehr im Pkw-Besitz nicht zu erkennen. So nahm beispielsweise der Pkw-Bestand in den Niederlanden und Deutschland zwischen 2008 und 2017 um 11 \% bzw. 12 \% zu (Eurostat 2019), sodass mittelfristig weiterhin von einer Dominanz des Pkws in der An- und Abreise und Vor-Ort-Mobilität ausgegangen werden muss.

\subsubsection{Alternative Antriebe und $\mathrm{CO}_{2}$-Ziele für Fahrzeuge im Straßenverkehr}

Große Erwartungen werden in die Umstellung auf energieeffizientere und alternative, nichtfossile Antriebe gesetzt, um nicht vermeidbaren motorisierten Verkehr auch im Tourismus klimaschonender zu machen. Beispielsweise fordert die EU zur Erreichung ihrer Klimaziele eine Reduzierung des $\mathrm{CO}_{2}-$ Ausstoßes von neu zugelassenen Pkws von $15 \%$ bis zum Jahr 2025 und von $37,5 \%$ bis 2030 gegenüber dem bestehenden Flottenverbrauchsziel von 2021 (AustriaTech 2019).

Eine Möglichkeit zur Erreichung dieser Ziele ist neben der Steigerung der Energieeffizienz der konventionell angetriebenen Fahrzeuge die Elektromobilität, wenn diese entsprechend $\mathrm{CO}_{2}$-arm bzw. $\mathrm{CO}_{2}$-frei produzierten Strom nutzt. Im Vergleich zu konventionell angetriebenen Pkws zeigt die Mehrzahl aktueller Studien in der Gesamtbilanz aus Betrieb, Fahrzeugherstellung und Energieerzeugung Energieeffizienzgewinne und Emissionsminderungen sowohl bei Treibhausgasen als auch lokalen Luftschadstoffen (s. z. B. Umweltbundesamt 2018a; IEA 2019; Wietschel et al. 2019). Dies würde sich entsprechend positiv auf die im Tourismus durch den motorisierten Individualverkehr ausgestoßenen Emissionen auswirken. Allerdings hängen die erzielbaren Minderungen von Treibhausgasemissionen neben der Marktdurchdringung stark von der gesamten Lebenszyklusbilanz inklusive Fahrzeug- und Batterieproduktion und der Art der Elektrizitätsproduktion ab (IEA 2019; Wietschel et al. 2019). Zur Berechnung des Ausmaßes potenzieller Reduktionen von Treibhausgasemissionen beim Einsatz von Elektrofahrzeugen im Vergleich zu konventionellen Pkws bei der An- und Abreise und Vor-Ort Mobilität im Tourismus müssten entsprechend die jeweiligen nationalen Daten zum Strommix herangezogen werden. Entsprechende Berechnungen für Österreich über alle Herkunftsländer liegen nicht vor.

Die Akzeptanz und Marktdurchdringung elektrischer Pkws wiederum hängt von der Anzahl verfügbarer Modelle, Betriebs- und Anschaffungskosten, Verfügbarkeit und Preis von Rohstoffen für die Batterietechnik, Reichweiten sowie verfügbaren Lademöglichkeiten ab (s. z. B. Gass et al. 2014; Stark et al. 2014; Jellinek et al. 2015; Harrison und Thiel 2017; BDEW 2019). Unter sehr optimistischen Annahmen der Fortführung existierender Fördermaßnahmen und des Trends steigender Attraktivität wird mit einem Bestand an ElektroPkw (batterieelektrisch und Hybrid) von knapp 1,2-1,3 Mio. im Jahr 2030 und knapp 4,5 Mio. (oder ca. 20 \% bzw. $69 \%$ der Flotte bei steigender Gesamtzahl an Pkws) im Jahr 2050 in Österreich gerechnet (Umweltbundesamt 2019). Ähn- 
liche Anteile elektrisch angetriebener Pkw werden für den gesamten europäischen Markt und damit für die Herkunftsländer des österreichischen Tourismus erwartet (IEA 2019). Diese Annahme beruht nicht zuletzt auf der zunehmenden Zahl an Ländern und Städten Europas, in denen der Verkauf bzw. die Nutzung konventionell betriebener Fahrzeuge reduziert werden soll, beispielsweise in Norwegen ab 2025, den Niederlanden ab 2030 und Frankreich ab 2040 (Berylls 2018, 2019). Die Produktionspläne der Automobilhersteller in Anbetracht der verschärften $\mathrm{CO}_{2}$-Emissionsziele der EU lassen erwarten, dass elektrische Pkws in den nächsten Jahren den Massenmarkt erreichen und elektrische Lkws auch für den Güterverkehr zunehmend relevant werden (T\&E 2019a, b). Derzeit dominieren jedoch weiterhin konventionelle Fahrzeuge sowohl in Österreich als auch den Herkunftsländern, hohe Anteile alternativ angetriebener Pkws bei den Neuzulassungen sind lediglich in Norwegen und den Niederlanden zu verzeichnen (Eurostat 2019).

Ein erfolgreicher Übergang zur Elektromobilität hängt somit stark von unterstützenden Politikmaßnahmen ab, insbesondere der umweltgerechten Anlastung von Klimakosten (z. B. durch $\mathrm{CO}_{2}$-Steuern), Maßnahmen zum Ausbau der Ladeinfrastruktur, langfristigen Flottengrenzwerten für Treibhausgasemissionen und Subventionen in der Übergangsphase, bis Fahrzeuge mit alternativen Antrieben massenmarktfähig sind und wettbewerbsfähige Kaufpreise erzielt werden können (Harrison und Thiel 2017).

Für den Tourismus bedeutet ein zunehmender Anteil an Elektrofahrzeugen in den Herkunftsmärkten, dass die entsprechende Ladeinfrastruktur zur Verfügung gestellt werden muss. Für 2019/2020 hat die österreichische Bundesregierung in Kooperation mit den Fahrzeugimporteuren ein weiteres Programm zur Förderung der Elektromobilität für Unternehmen, Gemeinden und Vereine aufgelegt, das auch die Förderung von E-Fahrrädern, E-Transporträdern und leichten Lkws umfasst (Bundesverband Elektromobilität Österreich 2019). Letztere zwei können auch in touristischen Destinationen für die Vor-Ort-Mobilität und den Transport von Gütern Relevanz entwickeln. Zusätzlich bieten auch viele Bundesländer Förderungen an (Energiemagazin 2019). Gleichzeitig kann sich ein touristisches Angebot von E-Fahrzeugen (z. B. als Mietwagen oder Carsharingauto) positiv sowohl auf die Akzeptanz der Fahrzeuge als auch auf ein klima- und technologiefreundliches Image von Destinationen auswirken (Lubinsky et al. 2015).

Bei zunehmender Verbesserung der Fahrzeugflotten (z. B. Elektroantrieb) besteht allerdings auch die Gefahr, dass der Anreiz, umweltfreundlichere Verkehrsmittel bei An- und Abreise oder Vor-Ort-Mobilität aus Umweltschutzgründen zu nutzen, vermindert wird (Zech et al. 2013). Des Weiteren lösen alternative Antriebe nicht andere Umweltprobleme des motorisierten Verkehrs, wie z. B. Lärm und Flächeninanspruchnahme. Zudem wird eine Umstellung auf alternative Antriebe allein nicht ausreichen, um die Pariser Klimaziele und eine nahezu vollständige Dekarbonisierung des Verkehrs zu erreichen, sie ist jedoch eine dringend notwendige Maßnahme auf dem Weg dorthin (Gössling et al. 2010; Higham et al. 2013; Klementschitz et al. 2017; Umweltbundesamt 2019).

\subsubsection{Emissionsziele und Emissionshandel im Flugverkehr}

Im Jahr 2017 beschloss das 36. ICAO Council $\mathrm{CO}_{2}$-Emissionsstandards, die ab 2020 für neu zugelassene und ab 2023 für bereits bestellte Flugzeugtypen und ab 2028 für alle neu produzierten Flugzeuge gelten werden (ICAO 2017). Diese Grenzwerte werden bereits von den neueren Flugzeugtypen der großen Hersteller Boeing und Airbus eingehalten, sodass deren Effektivität begrenzt sein wird. Da gleichzeitig der Altersdurchschnitt von Flugzeugen derzeit weltweit ca. 11 Jahre beträgt (EASA 2019) und die Lebensdauer der heutigen Flugzeuge auf 30 Jahre ausgelegt ist (Airbus 2010), wird es ein bis zwei Jahrzehnte dauern, bis diese Grenzwerte vollständig wirksam werden.

Da gleichzeitig erwartet wird, dass der Luftverkehr gerade im Tourismus weiter stark wachsen wird (Peeters et al. 2007, 2016), sind daher flankierende Regulierungen notwendig, um signifikante Minderungen von Treibhausgasemissionen auch in diesem Sektor zu erreichen. Die Festlegung von Emissionszielen im Luftverkehrssektor erfordert aufgrund der grenzüberschreitenden Natur der Emissionsverursachung und der speziellen Regelungen für die Regulierung des Luftverkehrs ein sehr hohes Maß an internationaler Kooperation (BowsLarkin 2014). Aufgrund fehlender Einigungen zu internationalen Emissionszielen beschloss die Europäische Union ab 2012 die Einbindung des Luftverkehrs in den Europäischen Zertifikathandel EU-ETS (Emission Trading System; Europäische Kommission o.J.). Aufgrund internationalen politischen Drucks wurden Flüge, die außerhalb des europäischen Wirtschaftsraumes starten oder enden, zunächst temporär bis 2016 von dem Handel ausgenommen mit der Vorgabe, einen globalen marktbasierten Mechanismus zu entwickeln (siehe Wadud und Gühnemann 2016). Der ICAO-Rat beschloss 2016 die Einführung eines globalen Kompensationssystems namens CORSIA (Carbon Offsetting and Reduction Scheme for International Aviation) mit dem Ziel eines $\mathrm{CO}_{2}$-neutralen Wachstums im Flugverkehr ab 2020 (ICAO Assembly Resolution A39-3). Die Teilnahme an CORSIA erfolgt zunächst auf freiwilliger Basis in zwei dreijährigen Phasen 2021-2026, bevor verbindliche Teilnahmekriterien gelten. Dies führt dazu, dass 2021 für nur ca. 1,5\%, 2027 für etwa 11,5\% und 2039 für weniger als ein Viertel der Treibhausgasemissionen des Luftverkehrs eine Kompensation erfolgen wird (Scheelhaase et al. 2018; Maertens und Grimme 2019) und diese damit deutlich unter den Reduktionszielen des Pariser Klimaabkommens 
liegt. Daher sind auch für den internationalen Fernreiseverkehr nur sehr geringe Minderungen der Treibhausgasemissionen aus dieser Maßnahme zu erwarten. Die tatsächliche Minderung der Treibhausgasemissionen, auch bei bereits existierenden freiwilligen Kompensationsangeboten, hängt zudem stark von der Effizienz der Kompensationsmaßnahmen $a b$ und erfordert robuste Kriterien zur Zertifizierung potenzieller Kompensationsprojekte (Cames et al. 2016; Warnecke et al. 2019). Daten zum Anteil der bereits heute freiwillig von Fluggästen bezahlten $\mathrm{CO}_{2}$-Kompensationen liegen nicht vor.

Die Wirkung der bestehenden Einbindung innereuropäischer Flüge in das EU-ETS auf Flugpreise und Emissionen kann als gering betrachtet werden. Zum einen sind die angesetzten Emissionsobergrenzen für den Sektor mit einer statischen Reduzierung von $-5 \%$ gegenüber dem Durchschnitt von 2004 bis 2006 wenig ambitioniert, zum anderen werden derzeit $82 \%$ der Emissionszertifikate frei ausgegeben. Durch das gleichzeitige Überangebot von $\mathrm{CO}_{2}$-Zertifikaten im EUETS konnte zunächst keine signifikante Minderung an Emissionen des Luftverkehrs beobachtet werden (T\&E 2016). Der Preis der ETS- $\mathrm{CO}_{2}$-Zertifikate hat sich zwar seit Beginn des Jahres 2018 bis zu seinem bisherigen Höchststand im Juli 2019 von ca. 9 auf $29 €$ pro Tonne $\mathrm{CO}_{2}$ mehr als verdreifacht (finanzen.net 2019), er liegt damit allerdings weiterhin deutlich unter den geschätzten Kosten, die zur Erreichung der Pariser Klimaziele notwendig wären, wie am folgenden Beispiel demonstriert wird. Beim Preisstand von $29 €$ würden für einen Hin- und Rückflug von Frankfurt nach Wien ca. 4,75€ für ETS-Zertifikate anfallen, wenn diese voll bezahlt werden müssten, bzw. 0,71 $€$ unter der Annahme von $85 \%$ freien Zertifikaten (bei angenommenen 0,164 Tonnen $\mathrm{CO}_{2}$-Emissionen; Climate Austria und BMNT o.J.). Im Vergleich dazu errechnet der Kompensationsrechner von Climate Austria und BMNT mit $7 €$ etwa das 1,5-Fache bzw. 10-Fache an notwendigen Kompensationszahlungen für Klimaschutzprojekte.

Zur Erreichung der Emissionsziele können alternative Kraftstoffe auf Basis von Biomasse sowie Power-to-Liquid-(PTL-) Kerosin auf Basis von erneuerbarem Strom eingesetzt werden. Bisher ist deren Marktdurchdringung aufgrund hoher Produktionskosten noch sehr gering. Ein umfassender Einsatz dieser alternativen Kraftstoffe in der Zukunft erfordert einen massiven Ausbau an Produktionskapazitäten in Konkurrenz zu anderen Sektoren, insbesondere dem Straßengüterverkehr. Hierbei ergeben sich Probleme der Verfügbarkeit nachhaltig produzierbarer Biomasse und steigender Preise, sodass die Kosten für alternative Kraftstoffe wesentlich höher sind als die Kosten für andere Minderungsmaßnahmen, z. B. Kompensationskosten (de Jong et al. 2017; Prussi et al. 2019), und ohne umfassende Subventionen nur eine geringe Reduktion der Treibhausgasemissionen erreicht werden kann (Peters et al. 2017).

Für den Tourismus bedeutet dies, dass es mittel- bis langfristig zur Erreichung der Klimaziele im Luftverkehr zu einer deutlichen Verteuerung der An- und Abreise mit dem
Flugzeug kommen wird, um die Kosten für notwendige Kompensationen, alternative Kraftstoffe oder neue Flugzeugtechnologien zu decken.

\subsubsection{Automatisiertes Fahren}

Eine weitere für die Tourismusmobilität bedeutsame Entwicklung ist das automatisierte Fahren, unter dem hier Nutzungen von Fahrzeugen mit unterschiedlichen Ausprägungen der Automatisierung, von teilautomatisierten Funktionen zur Unterstützung von Fahrern bis hin zu hoch- und vollautomatisiertem und autonomem Fahrbetrieb, verstanden wird. Vor allem hochautomatisiertes und autonomes Fahren kann langfristig zu Veränderungen im Mobilitätsverhalten sowohl bei Anreise als auch Mobilität vor Ort führen (Cohen und Hopkins 2019; Prideaux und Yin 2019). Einerseits könnten autonome Carsharingfahrzeuge oder Minibusse als Zubringer „Shuttles“ und lokale Verteiler für den Personennahverkehr ${ }^{4}$ insbesondere für die ,erste und letzte Meile“ und Vor-Ort-Mobilität von Touristinnen und Touristen den öffentlichen Verkehr kostengünstiger, flexibler und attraktiver gestalten und so einen Modal Shift vom eigenen Pkw hin zu klimaschonenden Alternativen bewirken (ERTRAC 2019; Soteropoulos et al. 2019).

Andererseits erhöhen hochautomatisierte und autonome Fahrzeuge die Attraktivität der Nutzung von Privat-Pkw gerade auf längeren Strecken wie bei der Anreise zu Tourismusdestinationen. Sie bieten höheren Komfort, Sicherheit und Nutzbarkeit der Reisezeit als derzeitige Fahrzeuge bei gleichzeitiger Wahrung der Privatsphäre und Möglichkeit des Transports größeren Gepäcks und erlauben individuelle Mobilität auch bis ins hohe Alter. Alle derzeitigen verfügbaren Modellrechnungen gehen daher davon aus, dass sich durch die Automatisierung die Verkehrsleistung im motorisierten Individualverkehr ohne eine entsprechende staatliche Regulierung weiter erhöhen wird (siehe z. B. Mliakis et al. 2017; Soteropoulos et al. 2019). Dieses betrifft entsprechend auch die Tourismusmobilität. Nur im Falle einer gleichzeitigen Umstellung auf nichtfossile Antriebe, die durch autonome elektrische Sharingfahrzeuge beschleunigt werden könnte (Jones und Leibowicz 2019), ließen sich Reduktionen bei Treibhausgasemissionen erreichen, wobei noch erheblicher Forschungsbedarf über das Ausmaß der Einsparpotenziale besteht (May et al. 2018).

Dezidierte Abschätzungen der Folgen des automatisierten Fahrens für die Tourismusmobilität liegen derzeit für Österreich nicht vor. Cohen und Hopkins (2019) zeigen die Vielfalt denkbarer Einsatzformen autonomer und vernetzter

\footnotetext{
${ }^{4}$ Zur Erprobung dieser Technologien werden derzeit sowohl international als auch in unterschiedlichen Gebieten Österreichs Pilotprojekte, wie z. B. „Digibus $\AA$ Austria“ und ,,auto.Bus Seestadt“", durchgeführt (BMVIT 2018).
} 
Fahrzeuge im städtischen Tourismus, beispielsweise automatisierte Flughafenshuttles, Sightseeingtouren, Stadttaxen oder Mietwagen, welche zu neuen touristischen Möglichkeiten, veränderten sozialen Interaktionen sowie Chancen und Herausforderungen für eine klimaverträgliche städtische Verkehrsplanung führen. Letztere hängen sehr stark davon ab, in welchem Umfang autonome Fahrzeuge als individuelles (erhöhter Flächenverbrauch und Verkehrsbelastungen) oder Sharingangebot (mit Chancen z. B. zur Umwandlung von Parkplatzflächen in öffentliche Aufenthaltsräume) wahrgenommen werden (Cohen und Hopkins 2019).

\subsubsection{Kosten der Mobilität}

Ein wesentlicher Faktor für die Verkehrsmittelwahl sind die Kosten für die An- und Abreise und Vor-Ort-Mobilität (s. Abschn. 3.1.2). Geringer wahrgenommene Kosten bei Nutzung des eigenen Pkws, z. B. wenn die Abschreibungsund Betriebskosten nicht eingerechnet werden, lassen die Nutzung der Bahn für den Reisenden teurer erscheinen, insbesondere bei Fahrten mit mehreren Personen. Dadurch werden Bahnreisen nur für Vielfahrer mit entsprechenden Ermäßigungen oder Sparpreisangeboten als konkurrenzfähig wahrgenommen (vgl. Umweltbundesamt 2009).

Gleichzeitig mangelt es nach wie vor an Kostenwahrheit zwischen den Verkehrsträgern in der Anlastung gesellschaftlicher Kosten (van Essen et al. 2019). Beispielsweise sind internationale Flugreisen von Kraftstoff- und Mehrwertsteuern ausgenommen (Schönpflug et al. 2014) und, wie oben angeführt, unterliegen derzeit nur Flüge innerhalb des europäischen Wirtschaftsraumes dem europäischen Emissionszertifikatehandel. Hierdurch können beispielsweise Billigflugangebote Flugreisen im Vergleich zu Bahnreisen preislich äußerst attraktiv machen.

Diese Entwicklung hin zu günstigeren Flugreisen wurde außerdem durch operative und technologische Maßnahmen zur Effizienzsteigerung sowie die Deregulierung im Luftverkehr in Europa ab 1992 ermöglicht (Mundt 2006).

\subsubsection{Sharing}

Ein weiterer Trend mit potenziellen Auswirkungen auf das Mobilitätsverhalten von Reisenden ist die zunehmende Nutzung von Sharingangeboten im Verkehr (PwC 2017), die sowohl auf hohe Anschaffungs- und Versicherungskosten für Pkws gerade für Jüngere als auch auf steigendes Umweltbewusstsein und eine Tendenz weg vom materiellen Besitz zurückzuführen ist (Böcker und Meelen 2017; Hartl et al. 2018). Hier hat es in den letzten Jahren eine deutliche Zunahme von Sharingangeboten im Verkehr wie Free-Floating-Carsharing, Ride-Sharing, Bikesharing, E-Scooter-Sharing, Vermietungen von Elektromountainbikes etc. gegeben (Shaheen et al. 2018). Allerdings ist der Markt sehr dynamisch mit teilweisen Überangeboten und anschließendem Verschwinden von Marktanbietern (Arbeiterkammer Wien 2017). Gerade flexible, nicht stationsgebundene Angebote können vor allem für Städtereisende attraktiv sein und deren Mobilität vor Ort verbessern. Viele ländliche Tourismusgemeinden fördern ebenfalls einen Mix aus konventionellen öffentlichen Verkehrsmitteln und flexiblen, auf Sharingkonzepten basierenden Lösungen (Wallergraber et al. 2014).

Reduzierte Treibhausgasemissionen ergeben sich im Tourismus, wenn Sharingnutzerinnen und -nutzer auf die An- und Abreise mit dem Pkw zugunsten klimaschonender Alternativen verzichten und ihr Mobilitätsverhalten vor Ort ändern (Ludmann 2018; Shaheen et al. 2018). Weiters kann durch die Nutzung von E-Carsharing im Tourismus die Akzeptanz elektrischer Fahrzeuge gesteigert werden und so zu einem Übergang zur Elektromobilität beitragen (Lubinsky et al. 2015; Schlüter und Weyer 2019). Allerdings ist zu beachten, dass insbesondere Ride-Sharing und, in geringerem Umfang, stationsfreie Carsharingangebote zu einer Zunahme der Fahrleistungen im motorisierten Individualverkehr führen können und daher vor allem nur als Fahrzeuge mit alternativen Antrieben und nur dort gefördert werden sollten, wo nichtmotorisierte oder öffentliche Verkehrsmittel keine ausreichenden Alternativen darstellen (Hülsmann et al. 2018; Shaheen et al. 2018).

\subsubsection{Technologische Entwicklungen zur Unterstützung von Multimodalität}

Durch die zunehmende Bereitstellung und Nutzung von Onlinebuchungsdiensten und Smartphoneapplikationen wird es für Reisende einfacher, ihre Routen multimodal zu gestalten und Buchungen von Fahrkarten unterschiedlicher Anbieter zu kombinieren. Hierdurch kann die Nutzung klimaverträglicherer öffentlicher Verkehrsmittel als Teil einer multimodalen Kette anstelle einer Pkw-Nutzung attraktiver werden (ITS Austria 2018). Derzeit existieren österreichweit und international viele Initiativen, integrierte Buchungsplattformen für multimodale Mobilitätsservices zu entwickeln, die gleichzeitig personalisierte, preislich differenzierte Mobilitätsangebote ermöglichen (Schlagwort „Mobility as a Service“; Hietanen 2014; Holmberg et al. 2016; ITS Austria 2019). Allerdings gibt es noch erhebliche institutionelle Barrieren, beispielsweise Dateneigentümerschaft oder Regeln für Umsatzaufteilung, die eine Kooperation aller potenziell beteiligten Anbieter erschweren (Docherty et al. 2018). Zudem ist derzeit noch Gegenstand der Forschung, inwieweit diese Technologien tatsächlich zu einer Verlagerung auf umweltfreundliche Verkehrsmittel und zu einer Reduktion von Treibhausgasemissionen beitragen können, insbesondere im Tourismus (POLIS 2017). 
Tab. 3.3 Wirkungen von klimainduzierten Phänomenen auf Verkehr und Tourismusmobilität. (In Anlehnung an Abb. 2.11; eigene Darstellung nach Cavallaro et al. 2016)

\begin{tabular}{|c|c|c|c|c|}
\hline $\begin{array}{l}\text { Klimainduzierte } \\
\text { Phänomene } \\
\text { (Abb. 2.11) }\end{array}$ & $\begin{array}{l}\text { Überwiegend be- } \\
\text { troffene Verkehrs- } \\
\text { träger }\end{array}$ & $\begin{array}{l}\text { Wirkung Verkehr } \\
\text { Infrastruktur }\end{array}$ & Betrieb & Wirkung Tourismusmobilität \\
\hline \multirow[t]{2}{*}{ Hitze } & \multirow[t]{2}{*}{$\begin{array}{l}\text { Straße } \\
\text { Bahn }\end{array}$} & $\begin{array}{l}\text { Hitzeschäden an Infrastruktur/ } \\
\text { Brand entlang der Infrastruktur } \\
\text { durch Funkenflug }\end{array}$ & $\begin{array}{l}\text { Einschränkungen im } \\
\text { Betrieb }\end{array}$ & $\begin{array}{l}\text { Behinderung bei An-/Abreise } \\
\text { von/zu den Destinationen }\end{array}$ \\
\hline & & & $\begin{array}{l}\text { Hitzebelastung in nicht- } \\
\text { klimatisierten, privaten/ } \\
\text { öffentlichen Verkehrs- } \\
\text { mitteln }\end{array}$ & $\begin{array}{l}\text { Verkehrsmittelwahl (An-/ } \\
\text { Abreise - vor Ort) }\end{array}$ \\
\hline \multirow[t]{2}{*}{$\begin{array}{l}\text { Starknieder- } \\
\text { schläge (regional } \\
\text { oder lokal) }\end{array}$} & $\begin{array}{l}\text { Straße } \\
\text { Bahn }\end{array}$ & $\begin{array}{l}\text { Behinderung/Schäden/Zer- } \\
\text { störung der Infrastruktur durch } \\
\text { Murenabgänge, Hangrutschun- } \\
\text { gen, klein-/großräumige Über- } \\
\text { flutungen, Hochwässer }\end{array}$ & $\begin{array}{l}\text { Behinderung im } \\
\text { Straßenverkehr/Um- } \\
\text { leitungen; Zugausfälle/ } \\
\text { Verspätungen }\end{array}$ & $\begin{array}{l}\text { Behinderung bei An-/Abreise } \\
\text { von/zu den Destinationen }\end{array}$ \\
\hline & $\begin{array}{l}\text { Wasserstraße } \\
\text { Seen }\end{array}$ & Sperre von Anlegestellen & $\begin{array}{l}\text { Einschränkungen in der } \\
\text { Schiffbarkeit }\end{array}$ & $\begin{array}{l}\text { Einschränkung im Betrieb/ } \\
\text { Ausfall touristischer An- } \\
\text { gebote (Linienschiffe/Fluss- } \\
\text { kreuzfahrt) }\end{array}$ \\
\hline $\begin{array}{l}\text { Trockenheit/ } \\
\text { Trockenperioden }\end{array}$ & $\begin{array}{l}\text { Wasserstraße } \\
\text { Seen }\end{array}$ & Niederwasser & $\begin{array}{l}\text { Einschränkungen in der } \\
\text { Schiffbarkeit }\end{array}$ & $\begin{array}{l}\text { Einschränkung im Betrieb/ } \\
\text { Ausfall touristischer An- } \\
\text { gebote (Linienschiffe/Fluss- } \\
\text { kreuzfahrt) }\end{array}$ \\
\hline Schnee & $\begin{array}{l}\text { Straße } \\
\text { Bahn }\end{array}$ & $\begin{array}{l}\text { Behinderung/Schäden/Zer- } \\
\text { störung der Infrastruktur durch } \\
\text { Lawinenabgänge }\end{array}$ & $\begin{array}{l}\text { Sperre aufgrund von } \\
\text { Lawinengefahr }\end{array}$ & $\begin{array}{l}\text { Behinderung bei An-/Abreise } \\
\text { von/zu den Destinationen }\end{array}$ \\
\hline Wind & $\begin{array}{l}\text { Straße } \\
\text { Bahn } \\
\text { Flugverkehr }\end{array}$ & $\begin{array}{l}\text { Behinderungen/Schäden der } \\
\text { Verkehrsinfrastruktur (z. B. } \\
\text { durch umstürzende Bäume) }\end{array}$ & $\begin{array}{l}\text { (Flug-)Ausfälle/Ver- } \\
\text { spätungen }\end{array}$ & $\begin{array}{l}\text { Behinderung bei An-/Ab- } \\
\text { reise von/zu den Destina- } \\
\text { tionen }\end{array}$ \\
\hline
\end{tabular}

\subsection{Einfluss des Klimawandels bzw. Einfluss auf den Klimawandel}

\subsubsection{Einfluss des Klimawandels auf den Tourismusverkehr}

\section{Auswirkungen auf die Verkehrsinfrastruktur und den Betrieb von Mobilitätsangeboten}

Eine intakte Verkehrsinfrastruktur ist die Voraussetzung für die An- und Abreise der Gäste, aber auch für die Mobilität vor Ort. Die Begleiterscheinungen des Klimawandels, wie Extremtemperaturen und -niederschläge und damit verbunden Muren, Hangrutschungen oder Lawinenabgänge, Überflutungen unterschiedlichen Ausmaßes, aber auch Hitzeschäden auf Straßen und von Gleisen, beeinträchtigen nicht nur die Verkehrsinfrastruktur, sondern auch den Verkehrsfluss und die Verkehrsbedienung (Cavallaro et al. 2016). Aber auch der Flugverkehr kann durch Sturmböen betroffen und die Schifffahrt durch Hoch- oder Niederwasser in ihrem Betrieb eingeschränkt sein (Tab. 3.3).

Behinderungen in der An- und Abreise zu oder von den Tourismusdestinationen sind die Folge, die u. a. in den Nichtantritt von Urlauben und Stornierungen münden können. Die wirtschaftlichen Wirkungen sind derzeit nicht bekannt. Zwar gibt es eine Abschätzung zu den Kosten von klima- und wetterbedingten Schäden des österreichischen Straßennetzes (Steininger et al. 2015), die sich auf 27 Mio. $€$ pro Jahr in der ersten Jahrhunderthälfte bis zu rund 38 Mio. $€$ pro Jahr zur Mitte des 21. Jahrhunderts (in der Periode 2036-2065) belaufen. Diese beinhalten allerdings nicht die indirekten Kosten durch Folgewirkungen, wie z. B. durch die durch Schäden verursachten wirtschaftlichen Einbußen im Tourismus.

\section{Änderungen im Reiseverhalten und neue Wachstumsmärkte}

Weiters bewirkt der Klimawandel mit seinen Begleiterscheinungen Änderungen im Reiseverhalten. Die Schneeunsicherheit in den Wintermonaten stärkt die Attraktivität schneeunabhängiger Destinationen (Abschn. 6.3.1). Hitzetage in den Sommermonaten fördern Angebote zur Sommerfrische für Städterinnen und Städter, auch für Kurzaufenthalte am Wochenende im Nahbereich der Städte (Tötzer \& Schaffler 2017; Juschten et al. 2019). Eine Untersuchung des Einflusses des Klimawandels 
auf die Tourismusmobilität in Südtirol geht davon aus, dass künftig auf Südtirols Straßen die tourismusbedingte Verkehrsintensität im Sommer doppelt so hoch wie im Winter sein wird, bedingt durch zunehmende Nachfrage im Sommertourismus und Verringerung der Nachfrage im Wintertourismus aufgrund der zu erwartenden Temperaturanstiege (Cavallaro et al. 2016).

Das geänderte Reiseverhalten (Abschn. 6.3.1, 7.3.1) hat somit in weiterer Folge auch Auswirkungen auf das Verkehrsaufkommen und die Verkehrsleistungen sowie auf die Verkehrsmittelwahl. Einerseits handelt es sich um zeitliche Verlagerungen, die sich in der Gesamtbilanz der tourismusbedingten Treibhausgase über ein Jahr gesehen nicht niederschlagen. Andererseits sind es örtliche Verlagerungen innerhalb von Österreich (Kap. 6). Diese örtlichen Verlagerungen können Umwelteffekte durch temporäre Verkehrsüberlastungen nach sich ziehen und sich zudem durch geänderte Entfernungen und Erreichbarkeiten der Quellmärkte und eine damit verbundene evtl. Änderung der Verkehrsmittelwahl auf die Treibhausgasbilanz auswirken.

Andererseits steigt die Zahl an Gästen aus weiter entfernten Wachstumsmärkten, bemerkbar auch an den steigenden Passagierzahlen der destinationsnahen Flughäfen (z. B. Innsbruck). Diese Märkte weisen einen überdurchschnittlich hohen Anteil von An- und Abreisen mit dem Flugzeug auf, was sich in einer Zunahme der Treibhausgasemissionen niederschlagen wird (Abschn. 3.3.2).

Nachdem im Zusammenhang mit der sogenannten Coronakrise viele Fernreisende Schwierigkeiten bei der Rückkehr hatten, die Wirtschaftskraft reduziert ist und Fluglinien ebenfalls betroffen sind, könnte sich dieser Trend - zumindest kurzfristig - deutlich abschwächen.

\subsubsection{Einfluss des Tourismusverkehrs auf den Klimawandel ${ }^{5}$}

Auf globaler Ebene wird geschätzt, dass rund $8 \%$ der Emissionen aus dem Tourismus stammen und hierbei nahezu die Hälfte aus dem Verkehr, wobei der Flugverkehr eine große Rolle spielt (Lenzen et al. 2018; s. auch Abschn. 11.2). In Österreich ist der Verkehr einer der wesentlichen Emittenten in der österreichischen Treibhausgasbilanzierung. Im Jahr 2017 war der Verkehr für $29 \%$ der österreichischen $\mathrm{CO}_{2}$ Emissionen verantwortlich. Die Emissionen aus dem Verkehrssektor stiegen seit 1990 um rund $72 \%$ an, insbesondere aufgrund der zunehmenden Verkehrsleistung (Umweltbundesamt 2019). Die Verkehrsemissionen sind in erster Linie auf den Straßenverkehr zurückzuführen. Anzumerken ist,

\footnotetext{
${ }^{5}$ In vorliegendem Bericht wird ausschließlich auf die klimarelevanten Gase (Treibhausgase) eingegangen. Darüber hinausgehende Umweltwirkungen, wie Stickoxid- oder Staubemissionen, Lärm, Flächenverbrauch oder Landschaftszerschneidungen, werden nicht weiter beschrieben.
}

dass in der Inventur ausschließlich der nationale, nicht aber der internationale Flugverkehr berücksichtigt wird. Eine eindeutige Zuordnung der tourismusbedingten Verkehrsemissionen in der österreichischen Treibhausgasbilanzierung ist aus der vorhandenen Datenlage daher nicht möglich (siehe auch Verkehrsleistung, Abschn. 3.1.2 bzw. Abschn. 11.2.3). Zahlen zu den Klimawirkungen der Flusskreuzschifffahrt liegen nicht vor.

\subsubsection{Einfluss des Verkehrsmittels und der Distanz auf die Treibhausgasbilanz}

Die Wahl des Verkehrsmittels und in weiterer Folge die damit zurückgelegte Distanz sind essenziell für die Höhe der Treibhausgasemissionen, die eine Urlaubsreise verursacht (Umweltbundesamt 2018b).

Die höchsten Treibhausgasemissionen verursacht - gemessen an der gleichen Distanz - der Flug. Diese betragen rund das 5-Fache einer entsprechenden Fahrt mit dem Pkw. Deutlich besser und in diesem Sinne klimaschonender schneiden die Massenverkehrsmittel Bus und Bahn ab (Abb. 3.5) .

Anzumerken ist, dass die Höhe der Treibhausgasemissionen ebenso von dem Herkunftsmarkt abhängig ist. So ist bei einer von Unger (2018) ermittelten Reise einer Familie von Berlin nach Alpach der Unterschied zwischen Bahn und Bus deutlich geringer, da hier ein anderer Strommix bei der Bahn anzusetzen ist (vgl. Unger et al. 2016; Unger 2018).

Deutlicher fällt der Unterschied der verschiedenen Anreiseformen aus, wenn die unterschiedlichen Distanzen miteinbezogen werden. Eine aktuelle Untersuchung der Treibhausgasbilanz für unterschiedliche Urlaubsformen mit unterschiedlichen Verkehrsmitteln zeigt die vergleichsweise geringen Treibhausgasemissionen eines Österreichurlaubs im Vergleich zu Fernreisen, in denen sich sowohl das Verkehrsmittel „Flugzeug“ als auch die Entfernung der Urlaubsdestination widerspiegeln (Abb. 3.6) ${ }^{7}$. Die Berechnungen zeigen auch, dass die Emissionen bei Bahnanreise in Österreich zwischen einem Drittel bis zur Hälfte geringer als bei der Nutzung des Autos sind (Umweltbundesamt 2018b) ${ }^{8}$. Eine

\footnotetext{
${ }^{6}$ Pkw-Durchschnitt in Österreich 2017 (Diesel und Benzin gewichtet nach Verkehrsleistung in Österreich, durchschnittliche Größen- und Gewichtsklasse); Flugzeug gewichtet nach Inlandsflüge; Berücksichtigung klimarelevanter Auswirkungen in großer Höhe aufgrund physikalischen und chemischen Zusammenwirkens mit der Atmosphäre des RFI-Faktors (Radiative Forcing Index - Strahlungsantrieb). Beim Flugverkehr ist ein RFI Faktor (Radiative Forcing Index) von 2,7 (Empfehlung IPCC) berücksichtigt. Der Transfer von und zum Flughafen bzw. Bahnhof wird bei den Berechnungen vernachlässigt.

${ }^{7}$ Emissionen der Mobilität vor Ort sind in den Aktivitäten enthalten (z. B. Skibus, Ausflug).

8 Ähnliche Ergebnisse ergeben sich mit dem Ökologischen-FußabdruckRechner der TU Graz (http://www.fussabdrucksrechner.at/de).
} 


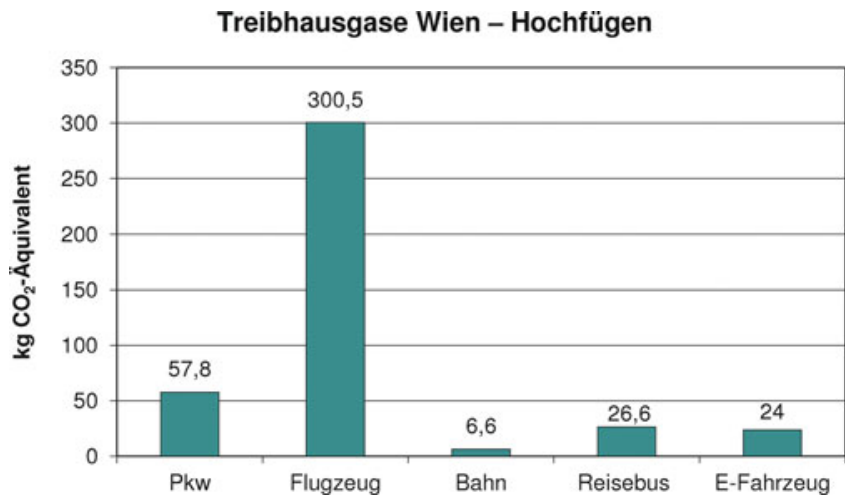

Abb. 3.5 Vergleich Treibhausgasemissionen pro Person nach unterschiedlichen Anreiseformen (Berechnungen mit GEMIS, Datenbasis 2017; direkte und indirekte Treibhausgasemissionen bei Anreise von Wien nach Hochfügen in Tirol nach Verkehrsmitteln, ausgehend von folgenden durchschnittlichen Besetzungsgraden: Pkw 2 Personen, Reisebus 19 Personen, Bahn 110 Personen, Flugzeug 33 Personen). (Grafik: Umweltbundesamt)

Darstellung der entfernungsabhängigen Treibhausgasemissionen nach unterschiedlichen Herkunftsländern ist zudem Abb. 11.2 bzw. Tab. 14.3 zu entnehmen.

Es sei darauf hingewiesen, dass selbst bei verhältnismäßig geringerem Anteil des Verkehrsmittels Flugzeug aufgrund der zurückgelegten Kilometer und der höheren Emissionsfaktoren insgesamt die Flugreisen bei den Treibhausgasemissionen höher zu Buche schlagen (Abschn. 11.2). Dies zeigen beispielsweise aktuelle Berechnungen des Carbon Footprint von Urlaubsreisen niederländischer Reiseveranstalter: Bei rund $72 \%$ der Reisen wird der Pkw zur Anreise genutzt, bei rund $19 \%$ das Flugzeug. Umgekehrt liegt der Anteil der im Jahr zurückgelegten Entfernung je Verkehrsmittel bei Pkw bei rund $24 \%$ und bei Flugzeugen bei rund $73 \%$. Dies schlägt sich in weiterer Folge im gesamten Carbon Footprint von Urlaubsreisen nieder: Rund $48 \%$ sind dem Verkehr zuzuordnen, davon werden rund $70 \%$ von Flugreisen verursacht (Eijgelaar et al. 2017). Ähnliches zeigt die Gegenüberstellung einer Untersuchung für Alpbach in Tirol durch Unger et al. (2016). Hier lag der Anteil der mit dem Flugzeug zurückgelegten Personenkilometer bei rund $13 \%$. Aufgrund der deutlich höheren Emissionsfaktoren von Flugzeugen im Vergleich zu anderen Verkehrsmitteln (Abschn. 11.2.) lag der Anteil an den vom Tourismusverkehr verursachten Treibhausgasemissionen bei $36,13 \%$, betrug also nahezu das 3-Fache.

\subsection{Anpassungs-, Minderungsmaßnahmen und Strategien}

\subsubsection{Anpassungsmaßnahmen und -strategien}

Die notwendigen Anpassungsstrategien an den Klimawandel für die Tourismusmobilität entsprechen im Wesentlichen jenen der Nationalen Anpassungsstrategie für den Verkehrssektor (BMNT 2017). In Zusammenhang mit der Behinderung und/oder Zerstörung der Verkehrsinfrastruktur durch Wetterereignisse und damit mit Behinderungen des Tourismusverkehrs sind insbesondere die folgenden Maßnahmen wesentlich:

- der weitere Ausbau von Informations- und Frühwarnsystemen,

- die Sicherung eines funktionsfähigen Verkehrssystems sowie

- die Überprüfung und allenfalls Anpassung von Rechtsnormen für Bau und Betrieb von Verkehrsinfrastrukturen unter geänderten klimatischen Bedingungen.

Anfang der 2010er-Jahre wurden von unterschiedlichen Verkehrsträgern bereits erste Überlegungen zur Klimawandel-
Abb. 3.6 Treibhausgasbilanz unterschiedlicher Urlaubstypen. (Umweltbundesamt 2018b)

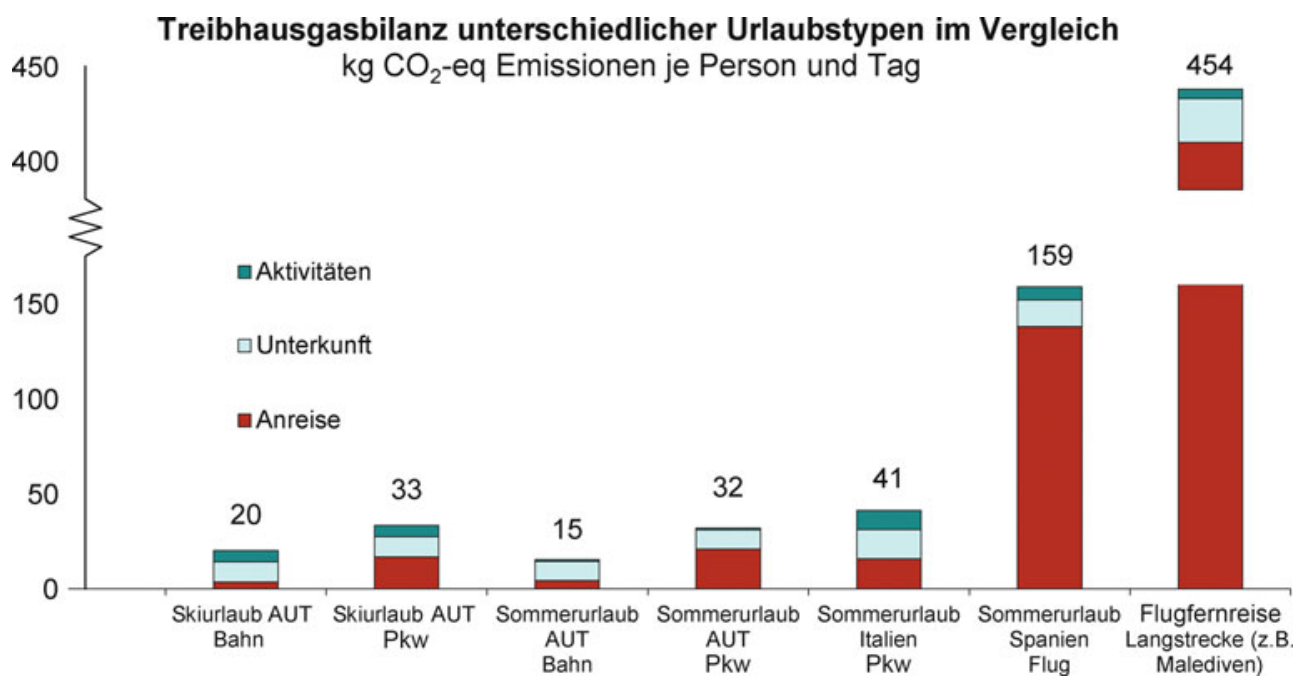


anpassung erstellt: Im Jahr 2012 wurden im Rahmen des Projektes KLIWA Anpassungsmaßnahmen an den Klimawandel für die Bahninfrastruktur erarbeitet (Umweltbundesamt 2013; ÖBB 2020), die Österreichische Wasserstraßen-GmbH, Viadonau, nahm an mehreren Projekten zur Anpassung an den Klimawandel teil, u. a. ECCONET (Viadonau 2015). Für das Straßennetz wurde seitens des Umweltbundesamtes ein Anpassungsfahrplan ausgearbeitet (Umweltbundesamt 2014).

Um insbesondere öffentliche Verkehrsmittel als attraktives Angebot sowohl für die An- und Abreise als auch für die Mobilität vor Ort zu erhalten, sind als Antwort auf zunehmende Hitzetage aus der Anpassungsstrategie (BMNT 2017) zudem folgende Maßnahmen relevant:

- Sicherstellung des thermischen Komforts durch Reduktion der thermischen Lasten in Verkehrsstationen und deren Umgebung,

- Reduktion von möglichen Hitzebelastungen für Fahrgäste und Personal in öffentlichen Verkehrsmitteln durch geeignete Klimatisierung.

Weiters sind die „Berücksichtigung von mikro-/mesoklimatischen Bedingungen bei der Stadt- und Freiraumplanung" sowie die „Reduktion des Zuwachses dauerhaft versiegelter Verkehrsflächen als Überflutungsschutz“ (BMNT 2017, S. 269 f.) wichtige Begleitmaßnahmen.

\subsubsection{Minderungsmaßnahmen und -strategien}

In Anlehnung an den Sachstandsbericht Mobilität (Umweltbundesamt 2018a) sind als Maßnahmen zur Minderung der Treibhausgasemissionen des Verkehrs die Strategien „Vermeiden, Verlagern, Verbessern“ zu sehen. Umgelegt auf die Tourismusmobilität bedeutet dies:

- Vermeidung touristischer Verkehre mit hohen Treibhausgasemissionen (insbesondere Flug- und Pkw-Verkehr, Abschn. 3.3.3), d. h. Reduktion der Anzahl oder der Länge touristischer Wege mit hohen Treibhausgasemissionen,

- Verlagerung der touristischen Verkehre auf treibhausgasarme Verkehrsmittel (Bus, Bahn, aktive Mobilität),

- klimaschonende Abwicklung der touristischen Verkehre.

Um erfolgreich wirken zu können, erfordern diese Maßnahmen sowohl politischen Willen und Programme als auch begleitende bewusstseinsbildende Maßnahmen bei allen Stakeholdern im Tourismus, die in Abschn. 3.5 dargestellt sind.

Da der Tourismus u. a. aus wirtschaftlicher Sicht sowie aus sozialen und kulturellen Gründen erwünscht ist, ist die Vermeidung von Reisewegen nur beschränkt eine adäquate Strategie. Einerseits kann auf die Reisedistanz Einfluss genommen werden. So sollte, u. a. um das Ausbleiben von Touristinnen und Touristen zu kompensieren, bei der Auswahl und Bewerbung von Herkunftsmärkten die Nachhaltigkeit (inklusive Klimaverträglichkeit) der Anreise ein wesentliches Kriterium sein. Aus Klimasicht muss es Ziel sein, die Tourismusherkunftsregionen möglichst lokal bzw. regional zu halten.

Zudem kann durch gezielte Urlaubswahl und -planung durch die Reisenden die Anzahl der Kurzurlaube zugunsten längerer Aufenthalte und damit die Anzahl an An- und Abreisewegen reduziert werden. Dieses wäre auch ein Ergebnis steigender Preise, bei einer vollen Anlastung der Klimakosten in den Mobilitätskosten (Krutzler et al. 2017; s. auch Abschn. 3.2).

Bei der Verlagerung der touristischen Verkehre auf treibhausgasärmere Verkehrsmittel geht es einerseits um die Verlagerung der Pkw-Anreise und Mobilität vor Ort auf den Umweltverbund (d. h. öffentlicher Verkehr, Radverkehr, Fußgängerverkehr). Hierfür ist es notwendig, dass für die gesamte Reisekette (inkl. Mobilität vor Ort) attraktive, nachhaltige Verkehrsmittel zur Verfügung stehen, die Information hierzu leicht zugänglich ist und auch entsprechende attraktive preisliche Angebote geschaffen werden. Hierfür sind jedoch oft gesetzliche, institutionelle, finanzielle und (informations-)technische Barrieren zu überwinden sowie sicherzustellen, dass Gäste grundsätzlich für die Thematik sensibilisiert werden und die entsprechenden Angebotsinformationen möglichst schon vor der Anreise erhalten (Agency for the Support of Regional Development Košice et al. 2018).

Anderseits muss aufgrund der hohen Treibhausgasemissionen des Luftverkehrs insbesondere das Verlagerungspotenzial von Flugreisen auf Fernzüge, speziell im europäischen Raum bzw. vom Hauptmarkt Deutschland ausgehend nach Österreich, ausgeschöpft werden. Eine Verlagerung der Fernreisen auf den Bahnverkehr entspricht auch der Zielsetzung der Europäischen Kommission im Weißbuch Verkehr (Europäische Kommission 2011). Hierzu ist es wichtig, Kostenwahrheit zwischen den Verkehrsträgern herzustellen, d. h. insbesondere die steuerlichen Minderbelastungen des Luftverkehrs im Vergleich zum Schienenverkehr abzubauen. Des Weiteren ist ein weiterer Ausbau des Zubringer- und Hochgeschwindigkeitsverkehrs auf der Schiene sowie eine Verbesserung des Dienstleistungsangebots, z. B. beim Gepäcktransport, notwendig (Maibach et al. 2018). Auch Fernbusse werden in Zukunft zunehmend als klimaverträglichere Alternative zu sehen sein.

Bereits seit mehreren Jahrzehnten gibt es in Österreich Projekte und Initiativen zu einer nachhaltigen Tourismusmobilität als Beitrag zum Klimaschutz, die es weiter auszubauen gilt, z. B.:

- Auf Bundesebene wurde eine Plattform „Tourismusmobilität“" geschaffen, die einen regelmäßigen Austausch mit relevanten Stakeholdern auf Landes- und auf 
regionaler Ebene betreibt. Des Weiteren werden von Bundesebene seit dem Jahr 2014 jährlich Tourismusmobilitätstage als wesentliche Netzwerkveranstaltungen organisiert (BMNT und BMVIT 2019). Im Jahr 2019 wurde der Praxisleitfaden „Wie wird meine Tourismusdestination nachhaltig mobil?" neu aufgelegt (BMNT und BMVIT 2019). Weiters läuft seit dem Jahr 2005 das nationale Förderprogramm klimaaktiv:mobil mit einem Beratungsprogramm zu Tourismus und Freizeitwirtschaft. Es gibt eine Vielzahl an Sammlungen von guten Beispielen, wie z. B. eine Übersicht über europäische Best-Practice-Beispiele und Empfehlungen für die Umsetzung bedarfsorientierter touristischer Mobilitätslösungen aus dem Interreg-Projekt „Last Mile“ (Agency for the Support of Regional Development Košice et al. 2018) oder „Inspirationen zur klimafreundlichen Tourismusmobilität“ aus dem Projekt „REFRESH! - Revival der Sommerfrische“ (Juschten et al. 2019).

- Das bekannteste Beispiel für nachhaltige Tourismusmobilität ist das Netzwerk „Alpine Pearls“, ein Zusammenschluss von touristischen Gemeinden im Alpenraum (in Österreich Werfenweng, Hinterstoder, Mallnitz, Weißensee und Neukirchen am Großvenediger), die Standards für nachhaltige Tourismusmobilität in ihren Destinationen aufgestellt haben und unterschiedliche Möglichkeiten der nachhaltigen Anreise und Mobilität für ihre Gäste anbieten. In Werfenweng konnte der Anteil der Gäste, die mit der Bahn anreisen, daraufhin vervierfacht und somit auf $28 \%$ erhöht werden (CIPRA 2010).

- Darüber hinaus gibt es zahllose regionale Beispiele für eine erfolgreiche Umsetzung von touristischen Mobilitätsprojekten, wie z. B. die Neusiedler See Card, eine touristische Mehrwertkarte, die u. a. die Nutzung von öffentlichen Verkehrsmitteln ermöglicht, die Bahnhofsshuttle in Kärnten und in Tirol oder das Projekt „Tirol auf Schiene", welches durch eine Kombination aus verbesserten Zugverbindungen und Investition in Kommunikationsmaßnahmen in den Herkunftsländern auf eine verstärkte Anreise von Urlaubsgästen mit der Bahn abzielt (Tirol Werbung o.J.).

Die umweltverträgliche Abwicklung des touristischen Verkehrs zielt auf den Einsatz emissionsarmer oder -freier Fahrzeugtechnologien und Treibstoffe ab. Diese ist stark an die allgemeine Entwicklung der Fahrzeugtechnologien und Grenzwerte gekoppelt, wie im vorherigen Abschnitt beschrieben, welche vor allem Initiativen auf europäischer und nationaler Ebene erfordern. ${ }^{9}$ Lokale Entscheidungsträgerinnen und -träger können die Umsetzung jedoch unterstützen, z. B.

\footnotetext{
9 Gleichzeitig muss darauf geachtet werden, dass Einsparungen bei Treibhausgasen nicht zu Erhöhungen bei anderen Schadstoffen oder Umweltwirkungen führen, die jedoch nicht Gegenstand dieses Reports sind.
}

durch gezielte Förderung notwendiger Ladeinfrastrukturen oder von E-Carsharingsystemen.

Im durch den Tourismus verursachten Güterverkehr können klimaschonende Lösungsansätze auf lokaler Ebene vor allem im Verteilerverkehr, z. B. durch Güterverteilzentren, die Förderung von emissionsarmen Logistikkonzepten oder durch Technologien wie elektrische Fahrzeuge und Lastenfahrräder, unterstützt werden, indem - ähnlich wie im Personenverkehr - Voraussetzungen zur Bereitstellung von Infrastrukturen geschaffen und längerfristig Einfahrbeschränkungen für hochemittierende Fahrzeuge ausgesprochen werden. Auf nationaler Ebene sind Lösungen im kombinierten Verkehr denkbar, diese erfordern allerdings einen konsequenten Ausbau der Schienenverkehrskapazitäten.

Eine Reduzierung und klimaschonende Abwicklung des Verkehrs durch Verlagerung und verbesserte Technologien kann sich durch eine verminderte Lärm- und Schadstoffbelastung wiederum positiv auf den Tourismus auswirken, sowohl in den besonders sensitiven Gebieten wie Alpentälern als auch in städtischen Bereichen. Durch sorgfältiges Design von energiesparenden Mobilitätslösungen im Personen- und Güterverkehr kann ein Zusatznutzen (sogenannte Co-Benefits) des Klimaschutzes erwirkt werden.

Eine Voraussetzung für eine umweltschonende Verkehrsmittel- und Technologiewahl auch im Tourismus ist die Anlastung der vollen gesellschaftlichen Kosten, hier insbesondere der Klimakosten, der Verkehrsträger, um Konsumentinnen und Konsumenten sowie Produzentinnen und Produzenten über Preissignale auch finanzielle Anreize für klimaverträgliche Entscheidungen zu geben. Ansätze hierzu existieren beispielsweise durch die Lkw-Maut, bei der bestimmte Umweltbelastungen eingerechnet werden dürfen, sowie in Form des $\mathrm{CO}_{2}$-Emissionszertifikatehandels im Flugverkehr innerhalb des EWR (Abschn. 3.2). Um maximal wirksam zu sein, müssen diese Ansätze jedoch vollständig auf alle Verkehre ausgedehnt werden und auch klimaschädliche Subventionen abgebaut werden. Insbesondere ist die Wirksamkeit des CORSIA-Kompensationsmechanismus (Abschn. 3.2) noch ungeklärt und erfordert genaueste Überwachung und gegebenenfalls flankierende Maßnahmen, wie zum Beispiel die Ausdehnung emissionsdifferenzierter Start- und Landegebühren oder $\mathrm{CO}_{2}$-Abgaben.

\subsection{Handlungsoptionen, Kommunikations- und Forschungsbedarf}

\subsubsection{Ansatzpunkte für Maßnahmen, die Überwindung von Barrieren und Kooperation}

Mobilität ist ein wesentlicher Bestandteil und Voraussetzung für Tourismus. In Bezug auf den Klimawandel treffen die 
Auswirkungen des Klimawandels auch das Verkehrssystem und hier die Anreise und den Komfort bzw. das Reiseverhalten der Touristinnen und Touristen selbst sowie in weiterer Folge deren Mobilitätsverhalten vor Ort. Weiterhin entscheidet die Anreiseform wesentlich über den Beitrag dieses Sektors zu den tourismusbedingten Treibhausgasen. Der Gast wählt hierfür bislang überwiegend den wenig klimaverträglichen Pkw, aber auch Flugreisen nehmen zu. Reisezeit, Preis und Komfort, aber auch fehlende Flexibilität vor Ort spielen hier eine entscheidende Rolle.

Wichtige Ansatzpunkte für Maßnahmen liegen in der Vermeidung nichtklimaschonender Mobilität, der Verlagerung auf klimaverträglichere Verkehrsmittel, wie Bahn, Bus oder Fahrrad, sowie in einer umweltverträglicheren Abwicklung durch den Einsatz moderner Technologien (Abschn. 3.4).

Die Ansatzpunkte für eine nachhaltige Tourismusmobilität wurden in Österreich prinzipiell erkannt, wie einige bereits bestehende Initiativen zeigen (Abschn. 3.4.2). Die oben beschriebenen Trends, wie die Zunahme autofreier Haushalte in Europas Großstädten, Ansätze für eine zunehmende Bewusstseinsbildung und auch künftige Preisentwicklungen nicht nachhaltiger Verkehrssysteme (Erhöhung von Flugkosten und verursachergerechte Anlastung von gesellschaftlichen Kosten), könnten hier Anstöße für die weitreichendere Umsetzung nachhaltiger Mobilitätskonzepte im Tourismus sein.

\subsubsection{Ansatzpunkte für die Akzeptanz von Maßnahmen, Information und Bewusstseinsbildung}

Entsprechende Befragungen (Abegg et al. 2019) zeigen, dass Bewusstsein über die Umweltschädlichkeit bestimmter Anreiseformen (Flugzeug, Pkw) vorhanden ist. In weiterer Folge ist die Bereitschaft von Urlauberinnen und Urlaubern, in den Destinationen vor Ort nachhaltigere Mobilitätsformen zu nutzen, gegeben, gering ist allerdings die Akzeptanz, auf die gewohnte Anreiseform (Flugzeug, Pkw) zu verzichten. Hier zeigt sich ein Ansatzpunkt für künftige Maßnahmen zur Bewusstseinsbildung und Verhaltensänderung der Reisenden.

Für die Umsetzung klimaschonender Mobilitätskonzepte sind die Einbindung und Kooperation von Stakeholdern aus dem Verkehrs- und Tourismusbereich gleichermaßen notwendig: Einerseits sind für den Gast attraktive Mobilitätsangebote für die Anreise und vor Ort zu schaffen, andererseits sind diese auch durch den Tourismus entsprechend an den Gast zu verkaufen und zu bewerben, z. B. über nachhaltig mobile Packages (Scuttari et al. 2016). Besonderes Augenmerk sollte im Sinne der Nachhaltigkeit auf die bedachtsame Bewerbung weit entfernter Märkte und die Vermittlung positiver Bilder alternativer Mobilitätsformen zum Pkw und Flugzeug fallen (Kap. 13).

Hierfür ist den Akteurinnen und Akteuren, insbesondere aus der Tourismusbranche, auf allen Ebenen (lokal, regional,
Länder und Bund) das Thema Nachhaltigkeit und Klimawandel im Tourismus besser bewusst zu machen.

\subsubsection{Wissenslücken und Forschungsbedarf}

Auch wenn das Thema der Tourismusmobilität in Österreich grundsätzlich bekannt ist und auch die Notwendigkeit zu handeln auf verschiedenen Ebenen gesehen wird, so sind die Datenlage und der Wissensstand um den Anteil des Tourismus an der Verkehrsleistung im Personen- und Güterverkehr und in weiterer Folge an den tourismusbedingten Treibhausgasemissionen mangelhaft. Zudem fehlen Informationen über das gruppenspezifische Mobilitätsverhalten von verschiedenen Urlaubersegmenten und deren Akzeptanz unterschiedlicher Mobilitätsangebote sowie über die Wirkung von Steuerungsund Lenkungsmaßnahmen. Diese Informationen wären für unterschiedliche weiterführende Aktionen notwendig:

- Aufnahme von Maßnahmen im Bereich der Tourismusmobilität in Klimaschutzkonzepte unterschiedlicher Ebenen und Abschätzung deren Wirkung,

- Ermittlung verschiedener Szenarien, z. B. von unterschiedlichen Energiepreisen auf das Verkehrsverhalten von Touristinnen und Touristen sowie von Bediensteten,

- systemdynamische Analyse von Wechselwirkungen zwischen Tourismus, Verkehr und Klimawirkungen sowie Reboundeffekten aus anderen Bereichen.

\subsection{Zusammenfassung}

Der Tourismus ist eng mit dem Thema Mobilität verknüpft. Für die Erreichbarkeit der Destinationen sind die entsprechende Verkehrsinfrastruktur, aber auch geeignete Mobilitätsangebote notwendig. Österreich bietet über sein hochrangiges Straßen- und Schienennetz und seine Flughäfen sehr gute überregionale und internationale Verbindungen. In peripheren Gebieten fehlen jedoch oft klimaschonende Angebote, die ähnliche Reisezeiten, Komfort und Flexibilität bieten wie der Pkw (hohe Übereinstimmung, mittlere Beweislage).

Entsprechend aktueller Befragungen nutzen rund $75 \%$ der Österreichurlauberinnen und -urlauber den Pkw für die Anreise zu ihrem Urlaubsort. Platz zwei bei der Verkehrsmittelwahl für die Anreise nimmt das Flugzeug mit rund $10 \%$ ein, die Bahn nutzen nur $8 \%$ der Reisenden (hohe Übereinstimmung, mittlere Beweislage). Diese Entwicklung wird durch den anhaltenden Trend zu Kurzurlauben mit möglichst kurzer An- und Abreise einerseits, aber auch durch die Erweiterung der Herkunftsmärkte, insbesondere auch weiter entfernter Märkte wie Russland oder Asien, forciert. Ebenso verringern geringer wahrgenommene Kosten bei Nutzung des eigenen Pkws und Billigflugangebote die Bereitschaft, klimaverträg- 
lichere Verkehrsmittel, wie die Bahn, zu nutzen. Darüber hinaus spielen Komfort und Flexibilität am Urlaubsort eine entscheidende Rolle bei der Verkehrsmittelwahl (hohe Übereinstimmung, mittlere Beweislage).

Somit werden für die Anreise vorwiegend jene Verkehrsmittel genutzt, die aus Klimasicht auch die höchsten Treibhausgasemissionen verursachen - das Flugzeug und der Pkw. Auf globaler Ebene wird geschätzt, dass rund 8 \% der Emissionen aus dem Tourismus stammen und hierbei nahezu die Hälfte aus dem Verkehr, wobei der Flugverkehr eine große Rolle spielt (hohe Übereinstimmung, mittlere Beweislage).

Aber auch der Klimawandel selbst beeinflusst den Tourismusverkehr: Hitze, Starkniederschläge und Schnee, aber auch Stürme können zu Schäden an den Verkehrsinfrastrukturen und somit zu Behinderungen bei der An- und Abreise oder in der Urlaubsdestination selbst führen, während anhaltende Trockenperioden Einschränkungen in der Schifffahrt bedingen können. Hier wird der Bedarf an entsprechenden Maßnahmen zur Klimawandelanpassung sowie eines geeigneten Managements im Krisenfall steigen. Schneeunsicherheiten in den Wintermonaten verstärken die Attraktivität schneeunabhängiger Destinationen. Hitzetage in den Sommermonaten wiederum fördern Angebote zur Sommerfrische für Städterinnen und Städter sowie Kurzaufenthalte im Nahbereich der Städte. Beide Entwicklungen sind mit einem zunehmenden Verkehrsaufkommen verbunden (hohe Übereinstimmung, mittlere Beweislage).

Um die negativen Klimawirkungen aus dem Tourismusverkehr gering zu halten, wird es in Zukunft notwendig sein, nicht nachhaltige Formen der Mobilität, wie den Flug- und Pkw-Verkehr, zu vermeiden oder auf klimaschonendere Verkehrsmittel zu verlagern bzw. den Tourismusverkehr insgesamt umweltverträglicher abzuwickeln (hohe Übereinstimmung, mittlere Beweislage).

Begünstigt werden kann eine Entwicklung hin zu nachhaltigen Mobilitätsformen durch den abnehmenden Pkwund Führerscheinbesitz in europäischen Großstädten sowie durch technologische Fortschritte und Entwicklungen auf dem Fahrzeugsektor, wie die Elektromobilität oder die Steigerung der Energieeffizienz von konventionell betriebenen Fahrzeugen. Sharingmodelle und Informationstechnologien, wie Onlinebuchungsdienste und Smartphoneapplikationen, sollen zudem die Nutzung klimaschonenderer Verkehrsmittel attraktivieren. Darüber hinaus wird es notwendig sein, das Angebot an klimaverträglichen Mobilitätsangeboten für die Anreise, aber auch für die Nutzung vor Ort entsprechend zu erweitern und nutzerfreundlich zu gestalten (mittlere Übereinstimmung, mittlere Beweislage).

Aus Klimasicht wird besonderes Augenmerk auf die Reduzierung des Flugverkehrs zu legen sein. Dies sollte insbesondere über Kostenwahrheit im Verkehr, bedachtsame Bewerbung weit entfernter Märkte und eine entsprechende Bewusstseinsbildung erfolgen (hohe Übereinstimmung, mittlere Beweislage).

\section{Kernaussagen - Kapitel 3}

- Die Anreise der Österreich-Urlauberinnen und -Urlauber ist nicht nachhaltig: 3 von 4 Gästen nutzen den Pkw und rund $10 \%$ das Flugzeug (hohe Übereinstimmung, gute Beweislage). Mit Erweiterung der Herkunftsmärkte ist unter den jetzigen Rahmenbedingungen zu erwarten, dass die Zahl der mit dem Flugzeug anreisenden Gäste zunehmen wird (hohe Übereinstimmung, mittlere Beweislage).

- Diese Anreiseformen, mit dem eigenen Pkw und vor allem mit dem Flugzeug, sind auch die Hauptverursacher der Treibhausgasemissionen im Tourismus (hohe Übereinstimmung, mittlere Beweislage).

- Hier sind Maßnahmen zur Vermeidung, Verlagerung und umweltverträglichen Abwicklung von Verkehren, sowohl bei der An- und Abreise als auch vor Ort, dringend notwendig (hohe Übereinstimmung, mittlere Beweislage). Dies kann erfolgen durch:

- Förderung von und Bewusstseinsbildung für verkehrsreduzierende Tourismusformen auf der Angebots- und Nachfragseite,

- Förderung und Erhöhung der Akzeptanz von nichtmotorisierten und öffentlichen Mobilitätsangeboten für die An- und Abreise sowie für die Mobilität vor Ort,

- volle Anlastung der Klimakosten bei allen Verkehrsmitteln,

- Bereitstellung von Infrastrukturen für Fahrzeuge mit alternativen Antrieben.

- Klimawandel betrifft das Reise- und damit das Verkehrsverhalten der Touristinnen und Touristen. Hier kann die Tourismusbranche mit lokalen und regionalen Angeboten dazu beitragen, dass Tourismusformen gewählt werden, die eine klimaschonendere An- und Abreise und Vor-Ort-Mobilität fördern (mittlere Übereinstimmung, mittlere Beweislage).

- Maßnahmen zur Klimawandelanpassung der Verkehrsinfrastruktur sowie des Verkehrsmanagements im Krisenfall zur Sicherstellung der Erreichbarkeiten sind notwendig (hohe Übereinstimmung, mittlere Beweislage).

\section{Literatur}

Abegg, B., Jänicke, L., Unger, R. \& Mailer, M. (2019): Alpine Winter Tourists' View on Climate Change and Travel Mobility. In: PröbstlHaider, U., Richins, H. \& Türk, S. (Hrsg.) Winter tourism: trends and challenges, S. 82-91. CABI, Wallingford, Vereinigtes Königreich.

Agency for the Support of Regional Development Košice, Environment Agency Austria, komobile w7, Naturpark Öewersauer, Regional Office for Spatial Planning of Westpomeranian Voivodeship (2018) Last mile: sustainable mobility for the last mile in tourism regions. Results of project phase 1. Online unter: https://www.interregeurope. 
eu/fileadmin/user_upload/tx_tevprojects/library/file_1534255578. pdf (letzter Zugriff: 28.04.2020).

Ahrens, G.-A., Wittwer, R., Hubrich, S., Wittig, S. \& Ließke, F. (2016) Sonderauswertung zum Forschungsprojekt „Mobilität in StädtenSrV 2013“, Städtevergleich. Verkehrs- und Infrastrukturplanung, TU Dresden, Deutschland. Online unter: https://tu-dresden.de/bu/ verkehr/ivs/srv/ressourcen/dateien/2013/uebersichtsseite/SrV2013 Staedtevergleich.pdf?lang=de (letzter Zugriff: 28.04.2020).

Airbus (2010) Airbus and the environment. AIRBUS S.A.S, Blagnac, Frankreich. Online unter: https://www.icao.int/environmental-protection/Documents/VoluntaryMeasures-Responses/France_Airbus. pdf (letzter Zugriff: 28.04.2020).

Anable, J. \& Gatersleben, B. (2005) All work and no play? The role of instrumental and affective factors in work and leisure journeys by different travel modes. Transportation Research Part A: Policy and Practice 39(2-3), 163-181. DOI: https://doi.org/10.1016/j. tra.2004.09.008

Arbeiterkammer Wien (2017) Branchenreport „Sharing economy“ 2017. AK Wien, Wien. Online unter: https://www.arbeiterkammer. at/infopool/wien/Branchenanalyse_Sharing_Economy_2017.pdf (letzter Zugriff: 28.04.2020).

AustriaTech (2019) Highlights der Elektromobilität 2018/19. AustriaTech - Gesellschaft des Bundes für technologiepolitische Maßnahmen GmbH, Wien, Österreich. Online unter: https://www.austriatech.at/assets/Uploads/Publikationen/PDF-Dateien/24020edb86/ Highlight_Report_2019.pdf (letzter Zugriff: 25.07.2019).

Bank Austria (2018) Branchenbericht Personentransport. UniCredit Bank Austria AG, Wien, Österreich. Online unter: https://www.bankaustria.at/files/Personentransport.pdf (letzter Zugriff: 28.04.2020).

BDEW (Bundesverband der Energie- und Wasserwirtschaft e. V.) (2019) Meinungsbild E-Mobilität: Meinungsbild der Bevölkerung zur Elektromobilität. BDEW Bundesverband der Energie- und Wasserwirtschaft e. V., Berlin, Deutschland. Online unter: https://www.bdew. de/media/documents/Awh_20190527_Fakten-und-Argumente-Meinungsbild-E-Mobilitaet.pdf (letzter Zügriff: 28.04.2020).

Berylls (2018) Verkaufs- und Zulassungsbeschränkungen von Fahrzeugen mit Verbrennungsmotor. Berylls Statements Oktober 2018. Berylls Strategy Advisors GmbH, München, Deutschland. Online unter: https:/www.berylls.com/statements/ (letzter Zugriff: 16.07.2019).

Berylls (2019) Fahrverbote in Europäischen Städten Treffen 12,6 Millionen Pkw direkt. Berylls Statements Mai 2019. Berylls Strategy Advisors GmbH, München, Deutschland. Online unter: https://www. berylls.com/statements/ (letzter Zugriff: 16.07.2019).

BFS \& ARE (2017) Verkehrsverhalten der Bevölkerung - Ergebnisse des Mikrozensus Mobilität und Verkehr 2015. Bundesamt für Statistik (BFS) und Bundesamt für Raumentwicklung (ARE), Neuchâtel, Schweiz. Online unter: https://www.are.admin.ch/are/de/home/verkehr-und-infrastruktur/grundlagen-und-daten/mzmv.html (letzter Zugriff: 21.07.2019).

BMNT (2017) Die österreichische Strategie zur Anpassung an den Klimawandel. Aktualisierte Fassung, Jänner 2017. Bundesministerium für Nachhaltigkeit und Tourismus (BMNT), Wien, Österreich. Online unter: https://www.bmlrt.gv.at/umwelt/klimaschutz/klimapolitik_national/anpassungsstrategie/strategie-kontext.html (letzter Zugriff: 28.04.2020).

BMNT (2019) Tourismus-Mobilitätstage. Bundesministerium für Nachhaltigkeit und Tourismus (BMNT), Wien, Österreich. Online unter: https://www.bmnt.gv.at/tourismus/tourismuspolitische-themen/ tourismusmobilitaet/tourismus-mobilitaetstage.html (letzter Zugriff: 24.07.2019).

BMNT \& BMVIT (2019) Wie wird meine Tourismusregion nachhaltig mobil? Anleitung für Praktikerinnen und Praktiker. Bundesministerium für Nachhaltigkeit und Tourismus (BMNT), Bundesministerium für Verkehr, Innovation und Technologie (BMVIT), Wien, Österreich. Online unter: https://www.klimaaktiv.at/service/
publikationen/mobilitaet/Anleitung-Praktiker.html (letzter Zugriff: 28.04.2020).

BMVIT (2013) Der Radverkehr in Zahlen: Daten, Fakten und Stimmungen. 2. Auflage. Bundesministerium für Verkehr, Innovation und Technologie (BMVIT), Wien, Österreich. Online unter: https://www. bmk.gv.at/themen/fuss_radverkehr/publikationen/riz.html (letzter Zugriff: 28.04.2020).

BMVIT (2014) Transeuropäische Verkehrsnetze (TEN-V). Bundesministerium für Verkehr, Innovation und Technologie (BMVIT), Wien, Österreich. Online unter: https://www.bmk.gv.at/themen/transport/ international_eu/eu/ten.html (letzter Zugriff: 28.04.2020).

BMVIT (2018) Áktionspaket Automatisierte Mobilität 2019-2022. Bundesministerium für Verkehr, Innovation und Technologie (BMVIT), Wien, Österreich. Online unter: https://www.bmk.gv.at/themen/alternative_verkehrskonzepte/automatisiertesFahren/aktionsplan.html (letzter Zugriff: 28.04.2020).

BMVIT (2020) Statistik Straße \& Verkehr. Bundesministerium für Verkehr, Innovation und Technologie (BMVIT), Wien, Österreich. Online unter: https:/www.bmk.gv.at/themen/strasse/publikationen/ statistik_strasseverkehr.html (letzter Zugriff: 28.04.2020).

Böcker, L. \& Meelen, T. (2017) Sharing for people, planet or profit? Analysing motivations for intended sharing economy participation. Environmental Innovation and Societal Transitions 23, 28-39. DOI: https://doi.org/10.1016/j.eist.2016.09.004

Bows-Larkin, A. (2014) All adrift: aviation, shipping, and climate change policy. Climate Policy 15(6), 1-22. DOI: https://doi.org/10. 1080/14693062.2014.965125

Bundesverband Elektromobilität Österreich (2019) Aktionspaket E-Mobilität 2019/2020. Bundesverband Elektromobilität Österreich (BEÖ), Maria Enzersdorf, Österreich. Online unter: http://www. beoe.at/aktionspaket-e-mobilitaet/ (letzter Zugriff: 08.02.2019).

Bursa, B. (2019) Modeling the intra-destination travel behavior of tourists. Unveröffentlichte/laufende Dissertation an der Fakultät für Technische Wissenschaften der Universität Innsbruck, Österreich.

Bursa, B. \& Mailer, M. (2018) Car-less on holiday? Sustainable tourist travel in Alpine regions. Präsentation bei der 2. Tourism Naturally Conference, 16. bis 18. Mai 2018in Kaprun, Österreich. Abstract online unter: https://fis.dshs-koeln.de/portal/files/3413210/TNC2018_ Book_of_Abstracts.pdf (letzter Zugriff: 28.04.2020).

Cames, M., Harthan, R.O., Füssler, J., Lazarus, M., Lee, C.M., Erickson, P. \& Spalding-Fecher, R. (2016) How additional is the Clean Development Mechanism? Analysis of the application of current tools and proposed alternatives (CLIMA.B.3/SERl2013/0026r). Institut für angewandte Ökologie (Öko-Institut e. V.), Berlin, Deutschland. Online unter: https://ec.europa.eu/clima/sites/clima/files/ets/docs/ clean_dev_mechanism_en.pdf (letzter Zugriff: 28.04.2020).

Campa, J.L., Ârce, R., López-Lambas, M. E. \& Guirao, B. (2018) Can HSR improve the mobility of international tourists visiting Spain? Territorial evidence derived from the Spanish experience. Journal of Transport Geography 73, 94-107. DOI: https://doi.org/10.1016/j. jtrangeo.2018.10.014

Cavallaro, F., Ciari, F., Nocera, S., Prettenthaler, F. \& Scuttaria, A. (2016) The impacts of climate change on tourist mobility in mountain areas. Journal of Sustainable Tourism 25(8), 1063-1083. DOI: https://doi.org/10.1080/09669582.2016.1253092

Chow, J.Y.J., Hernandez, S.V., Bhagat, A. \& McNally M.G. (2013) Multi-Criteria Sustainability Assessment in Transport Planning for Recreational Travel. International Journal of Sustainable Transportation 8(2), 151-175. DOI: https://doi.org/10.1080/15568318. 2011.654177

CIPRA (2010) Verkehr im Klimawandel. CIPRA compact 1/10. CIPRA International, Schaan, Liechtenstein. Online unter: https:/www. cipra.org/de/dossiers/18/826_de/inline-download (letzter Zugriff: 28.04.2020).

Climate Austria \& BMNT (o.J.) $\mathrm{CO}_{2}$-Rechner. Kommunalkredit Public Consulting $\mathrm{GmbH}$ und Bundesministerium für Nachhaltigkeit und 
Tourismus (BMNT), Wien, Österreich. Online unter: https://co2calc. climateaustria.at/co2calculator/main/co2flight?execution=e3s1 (letzter Zugriff: 20.07.2019).

Cohen, S.A. \& Hopkins, D. (2019) Autonomous vehicles and the future of urban tourism. Annals of Tourism Research 74, 33-42. DOI: https://doi.org/10.1016/j.annals.2018.10.009

Docherty, I., Marsden, G. \& Anable, J. (2018) The governance of smart mobility. Transportation Research Part A: Policy and Practice 115, 114-125. DOI: https://doi.org/10.1016/j.tra.2017.09.012

EASA (2019) Average aircraft age per flight has crept up towards 11 years. European Aviation Environmental Report. European Union Aviation Safety Agency (EASA). Online unter: https://www.easa. europa.eu/eaer/figures-tables/average-aircraft-age-flight-has-crepttowards-11-years (letzter Zugriff: 26.07. 2019).

Eijgelaar, E., Peeters, P.M., de Bruijn, K. \& Dirven, R. (2017) Travelling large in 2016. The carbon footprint of Dutch holidaymakers in 2016 and the development since 2002. NHTV Breda University of Applied Sciences, Breda, Niederlande. Online unter: https://www.cstt. nl/userdata/documents/travellinglarge2016-web.pdf (letzter Zugriff: 28.04.2020).

Energiemagazin (2019) Förderungen für Elektroautos in Österreich eine Übersicht der Bundesländer. Mad Dog Media GmbH, Leibnitz, Österreich. Online unter: https://www.energiemagazin.at/foerderungen-fuer-elektroautos-in-oesterreich-eine-uebersicht-der-bundeslaender/ (letzter Zugriff: 20.07.2019)

ERTRAC (2019). Connected Automated Driving Roadmap. European Road Transport Research Advisory Council (ERTRAC), Brüssel. Belgien. Online unter: https://www.ertrac.org/uploads/documentsearch/id57/ERTRAC-CAD-Roadmap-2019.pdf (letzter Zugriff: 28.04.2020).

van Essen, H., van Wijngaarden, L., Schroten, A., Sutter, D., Schmidt, M., Brambilia, S., El Beyrouty, K., Morgan-Price, S. \& Andrew, E. (2019) State of play of internalisation in the European transport sector. Europäische Kommission, Brüssel, Belgien. Online unter: https://ec.europa.eu/transport/sites/transport/files/studies/internalisation-state-of-play-isbn-978-92-76-01413-3.pdf (letzter Zugriff: 20.07.2019)

Europäische Kommission (2011) Weißbuch zum Verkehr. Fahrplan zu einem einheitlichen europäischen Verkehrsraum - Hin zu einem wettbewerbsorientierten und ressourcenschonenden Verkehrssystem. Amt für Veröffentlichungen der Europäischen Union, Luxemburg. Online unter: https://ec.europa.eu/transport/sites/transport/files/ themes/strategies/doc/2011_white_paper/white-paper-illustratedbrochure de.pdf (letzter Zugriff: 28.04.2020).

Europäische Kommission (o.J.) Reducing emissions from aviation. Europäische Union. Online unter: https://ec.europa.eu/clima/policies/ transport/aviation_en (letzter Zugriff: 20.07.2019).

Eurostat (2019) Passenger cars, by type of motor energy and size of engine - Eurostat. Europäische Union. Online unter: https://ec.europa.eu/eurostat/web/products-datasets/-/road_eqs_carmot (letzter Zugriff: 23.07.2019).

finanzen.net (2019) $\mathrm{CO}_{2}$ European emission allowances. finanzen.net $\mathrm{GmbH}$, Karlsruhe, Deutschland. Online unter: https://www.finanzen. net/rohstoffe/co2-emissionsrechte (letzter Zugriff 23.07.2019).

Flognfeldt, T. (2005) The tourist route system - models of travelling patterns. Belgeo 2015(1-2), 35-58. DOI: https://doi.org/10.4000/ belgeo.12406

Follmer, R., Josef, F., Tomschy, R., Sammer, G. \& Klementschitz, R. (2016) Österreich unterwegs 2013/2014: Ergebnisbericht zur österreichweiten Mobilitätserhebung „Österreich unterwegs 2013/2014“. Bundesministerium für Verkehr, Innovation und Technologie (BMVIT), Wien, Österreich. Online unter: https://www.bmk.gv.at/ themen/verkehrsplanung/statistik/oesterreich_unterwegs/berichte. html (letzter Zugriff: 29.04.2020).

Gass, V., Schmidt, J. \& Schmid, E. (2014) Analysis of alternative policy instruments to promote electric vehicles in Austria. Re- newable Energy 61, 96-101. DOI: https://doi.org/10.1016/j.renene.2012.08.012

Gössling, S., Hall, C.M., Peeters, P. \& Scott, D. (2010) The future of tourism: can tourism growth and climate policy be reconciled? A mitigation perspective. Tourism Recreation Research 35(2), 119-130. DOI: https://doi.org/10.1080/02508281.2010.11081628

Götz, K., Loose, W., Schmied, M. \& Schubert, S. (2002) Kurzfassung Mobilitätsstile in der Freizeit: Abschlussbericht des Projekts „, Minderung der Umweltbelastungen des Freizeit- und Tourismusverkehrs ". Institut für sozial-ökologische Forschung (ISOE) $\mathrm{GmbH} \&$ Institut für angewandte Ökologie (Öko-Institut e. V.), Frankfurt am Main, Deutschland. Online unter: https://www.umweltbundesamt. de/sites/default/files/medien/publikation/short/k2293.pdf (letzter Zugriff: 28.04.2020).

Gronau, W. \& Kagermeier, A. (2007) Key factors for successful leisure and tourism public transport provision. Journal of Transport Geography. 15(2), 127-135. DOI: https://doi.org/10.1016/j.jtrangeo.2006.12.008

Haefeli, U. \& Arnold, T. (2016) Autofreie Lebensstile - Spezialauswertungen der Mikrozensen Verkehr 1994, 2000, 2005 und 2010 sowie der Haushaltsbudgeterhebung. Bericht zuhanden des Bundesamts für Energie BFE, Inter-face Politikstudien Forschung Beratung, Luzern, Schweiz. Online unter: https://wohnbau-mobilitaet.ch/ fileadmin/user_upload/Downloads_PAWO/Bericht_Autofreie_Lebensstile_2016.pdf (letzter Zugriff: 28.04.2020).

Harrison, G. \& Thiel, C. (2017). An exploratory policy analysis of electric vehicle sales competition and sensitivity to infrastructure in Europe. Technological Forecasting and Social Change 114, 165178. DOI: https://doi.org/10.1016/j.techfore.2016.08.007

Hartl, B., Sabitzer, T., Hofmann, E. \& Penz, E. (2018) "Sustainability is a nice bonus" the role of sustainability in carsharing from a consumer perspective. Journal of Cleaner Production 202, 88-100. DOI: https://doi.org/10.1016/j.jclepro.2018.08.138

Herry, M. \& Sedlacek, N. (2014) Modal Split im Güterverkehr. Kammer für Arbeiter und Angestellte für Wien (AK Wien), Wien, Österreich. Online unter: https://www.arbeiterkammer.at/infopool/wien/Verkehr und Infrastruktur 52 neu.pdf (letzter Zugriff: 28.04.2020).

Herry, M., Schuster, M. \& Russ, M. (1999) Modellvorhaben „, Sanfte Mobilität-autofreier Tourismus ": Mobilitätsanalyse Gemeinde Bad Hofgastein. Forschungsarbeiten aus dem Verkehrswesen Band 94. Bundesministerium für Wissenschaft und Verkehr, Wien, Österreich.

Herry, M., Sedlacek, N. \& Steinacher, I. (2012) Verkehr in Zahlen Österreich, Ausgabe 2011. Bundesministerium für Verkehr, Innovation und Technologie (BMVIT), Wien, Österreich. Online unter: https:// www.bmk.gv.at/themen/verkehrsplanung/statistik/viz11.html (letzter Zugriff: 28.04.2020).

Hietanen, S. (2014) Mobility as a service - the new transport model? Eurotransport 12(2), ITS \& Transport Management supplement 2014, 2-4.

Higham, J., Cohen, S.A., Peeters, P. \& Gössling, S. (2013) Psychological and behavioural approaches to understanding and governing sustainable mobility. Journal of Sustainable Tourism 21(7), 949-967. DOI: https://doi.org/10.1080/09669582.2013.828733

Holmberg, P.-E., Collado, M., Sarasini, S. \& Williander, M. (2016) Mobility as a service - MAAS: describing the Framework. RISE Research Institutes of Sweden, Göteborg, Schweden. Online unter: https://www.transport20.no/wp-content/uploads/2016/06/maas.pdf (letzter Zugriff: 28.04.2020).

Hülsmann, F., Wiepking, J., Zimmer, W., Sunderer, G., Götz, K., Sprinke, Y., Hacker, F., Kasten, P., Schmolck, B., Schönau, M., Waldenfels, R. \& Birzle-Harder, B. (2018) share - Wissenschaftliche Begleitforschung zu car2go mit batterieelektrischen und konventionellen Fahrzeugen. Forschung zum free-floating Carsharing, Abschlussbericht. Öko-Institut e. V., Freiburg und ISOE - Institut für sozial-ökologische Forschung, Frankfurt am Main, Deutschland. Online unter: https://www.oeko.de/fileadmin/oekodoc/share-Wissen- 
schaftliche-Begleitforschung-zu-car2go-mit-batterieelektrischenund-konventionellen-Fahrzeugen.pdf (letzter Zugriff: 03.06.2020).

ICAO (2017) ICAO Council adopts new $\mathrm{CO}_{2}$ emissions standard for aircraft. International Civil Aviation Organisation (ICAO). Online unter: https://www.icao.int/Newsroom/Pages/ICAO-Council-adoptsnew-CO2-emissions-standard-for-aircraft.aspx (letzter Zugriff: 26.07.2020).

IEA (2019) Global EV Outlook 2019 -Scaling-up the transition to electric mobility. International Energy Agency (IEA), Paris, Frankreich. Online unter: https://webstore.iea.org/download/direct/2807?fileName=Global_EV_Outlook_2019.pdf (letzter Zugriff: 25.07.2019).

ITS Austria (2018). digital: vernetzt: mobil. AustriaTech - Gesellschaft des Bundes für technologiepolitische Maßnahmen GmbH, Wien, Österreich. Online unter: https://www.austriatech.at/assets/Uploads/ Publikationen/PDF-Dateien/c0699d9c4c/ITS-Austria-Arbeitsprogramm-2018.pdf (letzter Zugriff: 28.04.2020).

ITS Austria (2019) Mobilität als Service im Mittelpunkt des ITS Forums. AustriaTech - Gesellschaft des Bundes für technologiepolitische Maßnahmen GmbH, Wien, Österreich. Online unter: https://www. austriatech.at/de/maas-its-forum/ (letzter Zugriff: 28.04.2020).

Jamnig, M. (2019) Brexit: Auswirkungen-Mögliche Auswirkungen des Brexits auf den Tourismus. Stand 18.3. Österreich Werbung, Wien, Österreich. Online unter: https://www.austriatourism.com/fileadmin/ user_upload/Media_Library/Downloads/GBR/Brexit-Moegliche Auswirkungen_18.3..pdf (letzter Zugriff: 28.04.2020).

Jellinek, R., Emmerling, B., Pfaffenbichler, P. (2015) Electromobility in Austria - Results from COMPETT - an Electromobility + project. Austrian Energy Agency (AEA), Wien, Österreich. Online unter: https://www.researchgate.net/publication/319207814_Electromobility_in_Austria_-_Results_from_COMPETT_-_an_Electromobility_project_Work_Package_4_Report (letzter Zugriff: 28.04.2020).

Jones, E.C. \& Leibowicz, B.D. (2019) Contributions of shared autonomous vehicles to climate change mitigation, Transportation Research Part D: Transport and Environment 72, 279-298. DOI: https://doi.org/10.1016/j.trd.2019.05.005

de Jong, S., Hoefnagels, S.R., van Stralen, J., Londo, M., Slade, R., Faaij, A. \& Junginger, M. (2017) Renewable jet fuel in the European Union: scenarios and preconditions for renewable jet fuel deployment towards 2030. Faculty of Geosciences, Utrecht University, Niederlande. Online unter: https://www.uu.nl/sites/default/files/ renewable_jet_fuel_in_the_european_union_-_scenarios_and_preconditions_for_renewable jet_fuel_deployment towards_2030.pdf (letzter Zugriff: 28.04 .2020 ).

Juschten, M., Brandenburg, C., Hössinger, R., Liebl, U., Offenzeller, M., Prutsch, A., Unbehaun, W., Weber, F. \& Jiricka-Pürrer, A. (2019) Out of the city heat - way to less or more sustainable futures? Sustainability 11(1), 214. DOI: https://doi.org/10.3390/su11010214

Kasper, B. \& Scheiner, J. (2003) Nahverkehrsplanung für ältere Menschen, Handlungsansätze, Akzeptanz, Hemmnisse. Fachgebiet Verkehrswesen und Verkehrsplanung, Universität Dortmund, Deutschland. Online unter: http://www.vpl.tu-dortmund.de/cms/Medienpool/ PDF_Dokomunte/Arbeitspapiere/AP05_von_Birgit_Kasper_und Joachim Scheiner.pdf (letzter Zugriff: $2 \overline{-} 8.04 . \overline{2} 020$ ).

Klementschitz, R., Stark J. \& Link C. (2017) Electromobility scenarios and their impacts on sustainable development. In: Ladislav, O. \& Salaiova, B. (Hrsg.) Zborník prednášok konferencies Dopravav košickom regiónedo roku 2020, S. 199-207. Online unter: http:// www.arr.sk/file/aktuality_file494.pdf (letzter Zugriff: 28.04.2020).

Krutzler, T., Zechmeister, A., Stranner, G., Wiesenberger, H., Gallauner, T., Gössl, M., Heller, C., Heinfellner, H., Ibesich, N., Lichtblau, G., Schieder, W., Schneider, J., Schindler, I., Storch, A. \& Winter, R. (2017) Energie-und Treibhausgas-Szenarien im Hinblick auf 2030 und 2050. Umweltbundesamt GmbH, Wien, Österreich. Online unter: http:/www.umweltbundesamt.at/fileadmin/site/publikationen/ REP0628.pdf
Landesrecht Oberösterreich (2013) Gesamte Rechtsvorschrift Für Ö̈Bautechnikverordnung 2013. Bundesministerium für Digitalisierung und Wirtschaftsstandort, Wien, Österreich. Online unter: https:// www.ris.bka.gv.at/GeltendeFassung.wxe?Abfrage $=$ LROO\&Gesetzesnummer=20000727 (letzter Zugriff: 28.04.2020).

Lenzen, M., Sun, Y.Y., Faturay, F., Ting, Y.P., Geschke, A. \& Malik, A. (2018) The carbon footprint of global tourism. Nature Climate Change 8(6), 522-528. DOI: https://doi.org/10.1038/s41558-0180141-x

Lew, A.A. \& McKercher, B. (2002) Trip destinations, gateways and itineraries: the example of Hong Kong. Tourism Management 23(6), 609-621. DOI: https://doi.org/10.1016/S0261-5177(02)00026-2

Lichtenberger, E. (2001) Analysen zur Erreichbarkeit von Raum und Gesellschaft in Österreich. Verlag der Österreichischen Akademie der Wissenschaften (ÖAW), Wien, Österreich.

Lubinsky, A., Salama, P., Lipson, P., Torres, L. and Roy, B. (2015) Electric vehicle tourism in New York state. New York State Energy Research and Development Authority, Abany, NY, USA. Online unter: https:/www.wxystudio.com/uploads/2100021/1491839916811/ Electric-Vehicle-Tourism-in-New-York-State.pdf (letzter Zugriff: 28.04.2020).

Ludmann, S. (2018) Ökologie des Teilens: Bilanzierung der Umweltwirkungen des Peer-to-Peer Sharing. PeerSharing Arbeitsbericht 8. Institut für ökologische Wirtschaftsforschung (IÖW), Berlin, IZT - Institut für Zukunftsstudien und Technologiebewertung, Berlin und ifeu - Institut für Energie- und Umweltforschung, Heidelberg, Deutschland. Online unter: https://www.peer-sharing.de/data/ peersharing/user_upload/Dateien/Oekologie_des_Teilens_Arbeitspapier_8_pdf (letzter Zugriff: 03.06.2020).

Lue, C.-C., Crompton, J.L. \& Fesenmaier, D.R. (1993) Conceptualization of multi-destination pleasure trips. Annals of Tourism Research 20(2), 289-301. DOI: https://doi.org/10.1016/0160-7383(93)900569

Maertens, S. \& Grimme, W. (2019) CORSIA - Environmental effects and competitive implications. Präsentation bei der European Transport Conference (ETC), 9.-11. Oktober 2019, Dublin, Irland. Online unter: https://elib.dlr.de/129531/1/Maertens_CORSIA_ETC_2019. pdf (letzter Zugriff: 03.06.2020).

Maibach, M., Peter, M., Killer, M., Bieler, C., Zandonella, R., Notter, B. \& Bertschmann, D. (2018) Szenario Luftverkehr Deutschland unter Einbezug von Umweltaspekten. Umweltbundesamt, DessauRoßlau, Deutschland. Online unter: https://www.umweltbundesamt.de/sites/default/files/medien/1410/publikationen/2018-12-14 texte_109-2018-nachhaltige-gueterinfrastruktur.pdf (letzter Zugriff: 28.04.2020).

Mailer, M., Abegg, B., Jänicke, L. \& Bursa, B. (2019) Mobilitätsbedingte Klimawirkung einer alpinen Tourismusdestination: $\mathrm{CO}_{2}$-Bilanz und Einschätzung durch Touristen, Bewohner und Beschäftigte. Zeitschrift für Tourismuswissenschaft 11(2), 211-236. DOI: https:// doi.org/10.1515/tw-2019-0013

May, A.D., Sheperd, S., Pfaffenbichler, P. \& Emberger, G. (2018) The potential impacts of automated cars on urban transport: an exploratory analysis. In: Emberger, G. \& Shibayama, T. (Hrsg.) Impacts of new mobility services from the viewpoint of local communities and regions, S. 25-36. Institut für Verkehrswissenschaften, Technische Universität Wien, Österreich. Online unter: https://www.fvv. tuwien.ac.at/fileadmin/mediapool-verkehrsplanung/News/WCTRS/ Publication/Text_komplett.pdf (letzter Zugriff: 29.04.2020).

Mayer-Ertl, K., Holzer, V. \& Lung, E. (2015) Nachhaltige Mobilität im Tourismus erfordert kooperative Lösungen. Regionale Schienen 2015(3), 32-35. Online unter: https://www.bmk.gv.at/themen/alternative_verkehrskonzepte/tourismus/kooperativ.html (letzter Zugriff: 28.04.2020).

Meijer, J.R., Huijbregts, M. A., Schotten, K.C.G.J. \& Schipper, A.M. (2018) Global patterns of current and future road infrastructure. 
Environmental Research Letters 13(6), 064006. DOI: https://doi. org/10.1088/1748-9326/aabd42

Messerli, P. \& Trösch, M. (2002) Why it is not easy to change mobility behaviour in winter sports. Revue de Géographie Alpine 90(1), 6781. DOI: https://doi.org/10.3406/rga.2002.3073

Milakis, D., van Arem, B. \& van Wee, B. (2017) Policy and society related implications of automated driving: A review of literature and directions for future research. Journal of Intelligent Transportation Systems 21(4), 324-348. DOI: https://doi.org/10.1080/15472450.2 017.1291351

mobyome (o.J.) bedarfsverkehrat: Innovative Mobilitätslösungen für die letzte Meile in der Region. mobyome KG, Wien, Österreich. Online unter: https://www.bedarfsverkehr.at/content/Hauptseite (letzter Zugriff: 28.04.2020).

Mundt, J.W. (2006) Tourismus. Oldenbourg, München, Deutschland.

ÖBB (2020) ÖBB Klimaschutzstrategie 2030. ÖBB-Holding AG, Wien, Österreich. Online unter: https://presse.oebb.at/de/publikationen/ klimaschutzstrategie-2030 (letzter Zugriff: 28.04.2020).

ONS (2016) Five facts about... cars. Office for National Statistics (ONS), Newport u. a., Vereinigtes Königreich. Online unter: https:// www.ons.gov.uk/economy/environmentalaccounts/articles/fivefactsaboutcars/2016-09-22 (letzter Zugriff: 22.07.2019).

ÖROK (2018) ÖROK-Erreichbarkeitsanalyse 2018 (Datenbasis 2016): Analysen zum ÖV und MIV. Österreichische Raumordnungskonferenz (ÖROK), Wien, Österreich. Online unter: https://www. oerok.gv.at/fileadmin/user_upload/publikationen/Schriftenreihe/203/ OEROK-SR_203_web.pdf (letzter Zugriff: 29.04.2020).

ÖROK (2019) ÖROK-Atlas. Österreichische Raumordnungskonferenz (ÖROK), Wien, Österreich. Online unter: https://www.oerok-atlas. at/ (letzter Zugriff: 10.11.2019).

Österreich Werbung (2019) Tourismus-Monitor Austria: T-MONA Urlauberbefragung 2017/18. Zur Verfügung gestellt von Österreich Werbung, Wien, Österreich.

Peeters, P., Higham, J., Kutzner, P., Cohen S. \& Gössling, S. (2016) Are technology myths stalling aviation climate policy? Transportation Research Part D: Transport and Environment 44, 30-42. DOI: https://doi.org/10.1016/j.trd.2016.02.004

Peeters, P., Szimba, E. \& Duijnisveld, M. (2007) Major environmental impacts of European tourist transport. Journal of Transport Geography 15(2), 83-93. DOI: https://doi.org/10.1016/j.jtrangeo.2006.12.007

Peters, M., Pikkemaat, B., Gurgiser, W., Mailer, M., Tischler, S., Schermer, M., Stotten, R., Abegg, B. \& Steiger, R. (2017) Bleibt alles anders? Tourismus 2025. Universität Innsbruck, Österreich. Im Auftrag des Bundesministeriums für Wissenschaft, Forschung und Wissenschaft (BMWFW). Online unter: https://www.bmlrt.gv.at/ service/publikationen/tourismus/studie-tourismus-2025.html (letzter Zugriff: 29.04.2020).

POLIS (2017) Mobility as a service: implications for urban and regional transport. Polis Traffic Efficiency \& Mobility Working Group, Brüssel, Belgien. Online unter: https://www.polisnetwork.eu/wp-content/ uploads/2019/06/polis-maas-discussion-paper-2017-final_-2.pdf (letzter Zugriff: 29.04.2020).

Prideaux, B. (2009) Transport: a key element in destination development and operations. In: Prideaux, B. (Hrsg.) Resort destinations: evolution, management and development, S. 79-111. ButterworthHeinemann, Oxford, Vereinigtes Königreich.

Prideaux, B. (2000) The role of the transport system in destination development. Tourism Management 21(1), 53-63. DOI: https://doi. org/10.1016/S0261-5177(99)00079-5

Prideaux, B. \& Yin, P. (2019) The disruptive potential of autonomous vehicles (AVs) on future low-carbon tourism mobility. Asia Pacific Journal of Tourism Research 24(5), 459-467. DOI: https://doi.org/1 0.1080/10941665.2019.1588138

Prussi, M., O’Connell, A. \& Lonza, L. (2019) Analysis of current aviation biofuel technical production potential in EU28. Biomass and Bioenergy 130, 105371. DOI: https://doi.org/10.1016/j.biombioe.2019.105371

PwC (2018) Share economy 2017: the new business model. PricewaterhouseCoopers $\mathrm{GmbH}$ Wirtschaftsprüfungsgesellschaft (PwC). Online unter: https://www.pwc.de/de/digitale-transformation/shareeconomy-report-2017.pdf (letzter Zugriff: 29.04.2020).

Rehman Khan, S.A., Qianli, D., SongBo, W., Zaman, K. \& Zhang, Y. (2017) Travel and tourism competitiveness index: the impact of air transportation, railways transportation, travel and transport services on international inbound and outbound tourism. Journal of Air Transport Management 58, 125-134. DOI: https://doi.org/10.1016/j. jairtraman.2016.10.006

Sabitzer, W. (2011) 50 Jahre Fußgängerzone. Öffentliche Sicherheit 11(7-8), 64. Online unter: https://www.bmi.gv.at/magazinfiles/2011/07_08/files/verkehrssicherheit.pdf (letzter Zugriff: 29.04.2020).

Salzburg Airport (2019) Sommerflugplan 2019: inkl. Vorschau auf bereits bekannte Winterstrecken 2019/20. Salzburger Flughafen GmbH, Salzburg, Österreich. Online unter: https://scb-website.s3.amazonaws.com/user_upload/files/Flugplan_Salzburg/Flugplan_Sommer-Winter 2019-2020.pdf (letzter Zugriff: 29.04.2020).

Sammer, G. (2013) Nachhaltige Mobilität für touristische Gebiete. In: Bracher, T., Dziekan, K., Gies, J., Huber, F., Kiepe, F., Reutter, U., Saary, K. \& Schwedes, O. (Hrsg.) HKV Handbuch der kommunalen Verkehrsplanung, Kap. 2.4.5.1 (68. Ergänzungs-Lieferung). VDEVerlag, Berlin, Deutschland,

Sammer, G., Klementschitz, R., Steininger, K., Schmid, C., Hausberger, S. \& Rexeis, M. (2009) Problemanalyse und Lösungskonzepte für den Güterverkehr in Österreich aus der Sicht der Bundesländer. Ive Forschungsberichte Nr. 01/2009. Wien, Graz. Online unter: https:// boku.ac.at/fileadmin/data/H03000/H85000/H85600/downloads/Bericht_2009_05_05_Gueterverkehr_in_OEsterreich.pdf (letzter Zugriff: 15.06 .2019$)$.

Scheelhaase, J., Maertens, S., Grimme, W. \& Jung, M. (2018) EU ETS versus CORSIA - A critical assessment of two approaches to limit air transport's CO 2 emissions by market-based measures. Journal of Air Transport Management 67, 55-62. DOI: https://doi.org/10.1016/j. jairtraman.2017.11.007

Schlüter, J. \& Weyer, J. (2019) Car sharing as a means to raise acceptance of electric vehicles: an empirical study on regime change in automobility. Transportation Research Part F: Traffic Psychology and Behaviour 60, 185-201. DOI: https://doi.org/10.1016/j. trf.2018.09.005

Schönpflug, K., Paterson, I. \& Sellner, R. (2014) Evaluierung der Flugabgabe: Update zur IHS Studie 2012. Studie im Auftrag des Bundesministeriums für Finanzen (BMF). Institut für Höhere Studien (IHS), Wien, Österreich. Online unter: https://irihs.ihs.ac.at/id/ eprint/2887/1/IHSPR6541150.pdf (letzter Zugriff: 29.04.2020).

Scuttari, A., Volgger, M. \& Pechlaner, H. (2016) Transition management towards sustainable mobility in Alpine destinations: realities and realpolitik in Italy's South Tyrol region. Journal of Sustainable Tourism 24(3), 463-483. DOI: https://doi.org/10.1080/09669582.2 015.1136634

Segert, A. (2012) Informationspraktiken, Technikaffinität und Alltagsmobilität. Institut für Höhere Studien (IHS), Wien, Österreich. Online unter: http://www.ssoar.info/ssoar/handle/document/33850 (letzter Zugriff: 29.04.2020).

Shaheen, S., Totte, H. \& Stocker, A. (2018). Future of mobility white paper. Institute of Transportation Studies, UC Berkeley (UCB), CA, USA. Online unter: https://escholarship.org/uc/item/68g2h1qv\#main (letzter Zugriff: 29.04.2020).

Soteropoulos, A., Berger, M. \& Ciari, F. (2019) Impacts of automated vehicles on travel behaviour and land use: an international review of modelling studies. Transport Reviews 39(1), 29-49. DOI: https:// doi.org/10.1080/01441647.2018.1523253 
Stark, J., Link, C., Simic, D. \& Bäuml, T. (2014) Required range of electric vehicles - an analysis of longitudinal mobility data. IET Intelligent Transport Systems 9(2), 119-127. DOI: https://doi. org/10.1049/iet-its.2013.0019

Statistik Austria (2011) Mobilität der privaten Haushalte 2009/10. Ergebnisse der Konsumerhebung 2009/10. Bundesanstalt Statistik Österreich, Wien, Österreich. Online unter: http://www.statistik.at/ web_de/statistiken/menschen_und_gesellschaft/soziales/ausstattung_privater_haushalte/055975.html (letzter Zugriff: 29.04.2020).

Statistik Austria (2016) Mobilität der privaten Haushalte 20014/15. Ergebnisse der Konsumerhebung 20014/15. Bundesanstalt Statistik Österreich, Wien, Österreich. Online unter: http://www.statistik.at/ web_de/statistiken/menschen_und_gesellschaft/soziales/ausstattung_privater_haushalte/110362.html (letzter Zugriff: 29.04.2020).

Statistik Austria (2018a) Schieneninfrastruktur in Österreich zum Stichtag 31. Dezember 2017 und 2018. Bundesanstalt Statistik Österreich, Wien, Österreich. Online unter: https://www.statistik.at/ web_de/statistiken/energie_umwelt innovation_mobilitaet/verkehr/ schiene/schienenfahrzeuge_bestand $/ 056540 . \mathrm{html}^{-}$(letzter Zugriff: 29.04.2020).

Statistik Austria (2018b) Verkehrsstatistik 2017. Bundesanstalt Statistik Österreich, Wien, Österreich. Online unter: https://www.statistik. at/web de/services/publikationen/14/index.html?includePage $=$ detaile $\overline{d V i e w \& s e c t i o n N a m e=V e r k e h r \& p u b I d=676 ~(l e t z t e r ~ Z u g r i f f: ~}$ 29.04.2020).

Statistik Austria (2019a) Luftfahrt. Bundesanstalt Statistik Österreich, Wien, Österreich. Online unter: http://www.statistik.at/web_de/statistiken/energie_umwelt_innovation_mobilitaet/verkehr/luftfahrt/ index.html (letzter Zugriff: 09.07.2019).

Statistik Austria (2019b) Tourismus-Satellitenkonto für Österreich. Bundesanstalt Statistik Österreich, Wien, Österreich. Online unter: http://www.statistik.at/web_de/statistiken/wirtschaft/tourismus/tourismus-satellitenkonto/wertschoepfung/index.html (letzter Zugriff: 16.07.2019).

Statistik Austria (2019c) Kraftfahrzeuge Bestand. Bundesanstalt Statistik Österreich, Wien, Österreich. Online unter: http://www.statistik. at/web de/statistiken/energie umwelt innovation mobilitaet/verkehr/strasse/kraftfahrzeuge_-_bestand/index.html (letzter Zugriff: 23.07.2019).

Statistik Austria (2019d) Urlaubs- und Geschäftsreisen Kalenderjahr 2018. Bundesanstalt Statistik Österreich, Wien, Österreich. Online unter: http://www.statistik.at/wcm/idc/idcplg?IdcService=GET_NATIVE_FILE\&RevisionSelectionMethod=LatestReleased\& $\overline{\mathrm{d} D o c N a m e}=121439$ (letzter Zugriff: 29.04 .2020 ),

Steininger, K.W., König, M., Bednar-Friedl, B., Kranzl, L., Loibl, W. \& Prettenthaler, F. (Hrsg.) (2015) Economic Evaluation of Climate Change Impacts: Development of a Cross-Sectoral Framework and Results for Austria. Springer, Cham, Schweiz.

STRATA, Karlsruhe Institute of Technology (KIT), Imperial College, DIW German Institute for Economic Research, Infas, IFSTAR, Virginia Tech, TØI, ITS (Institute for Transport Studies) University of Leeds \& SUSTRAC (2013) "Mobility Y" - The Emerging Travel Patterns of Generation $Y$. Institute for Mobility Research (ifmo), München, Deutschland. Online unter: https://www.ifmo.de/files/ publications_content/2013/ifmo_2013_Mobility_Y_en.pdf (letzter Zugriff: 29.04.2020).

T\&E (2016) Aviation ETS - gaining altitude: an analysis of the aviation EU ETS 2013-2015. European Federation for Transport and Environment AISBL, Brüssel, Belgien. Online unter: https://www. transportenvironment.org/sites/te/files/2016_09_Aviation_ETS_gaining_altitude.pdf (letzter Zugriff: 17.02.2020).

T\&E (2019a) Electric surge: carmakers' electric car plans across Europe 2019-2025. European Federation for Transport and Environment AISBL, Brüssel, Belgien. Online unter: https://www.transportenvironment.org/sites/te/files/publications/2019_07_TE_electric_cars_report_final.pdf (letzter Zugriff: 25.07.2019).
T\&E (2019b) E-trucks: European automakers' third and final chance to get electrification right. European Federation for Transport and Environment AISBL, Brüssel, Belgien. Online unter: https://www. transportenvironment.org/newsroom/blog/e-trucks-european-automakers $\% \mathrm{E} 2 \% 80 \% 99$-third-and-final-chance-get-electrification-right (letzter Zugriff: 25.07.2019).

Tirol Werbung (o.J.) Tirol auf Schiene. Tirol Werbung GmbH, Innsbruck, Österreich. Online unter: https://www.tirolwerbung.at/projects/tirolauf-schiene/ (letzter Zugriff: 12.05.2020).

Tötzer, T. \& Schaffler, V. (2017) Anpassung privater Akteure im Wintertourismus: Fallstudienbericht im Rahmen von PATCH:ES - Private Adaptation Threats and Chances: Enhancing Synergies with the Austrian NAS Implementation. Austrian Institute of Technology (AIT), Wien. Online unter: https://docplayer.org/70698325-Fallstudienbericht-anpassung-privater-akteure.html (letzter Zugriff: 29.04.2020).

Umweltbundesamt (2009) Erreichbarkeiten alpiner Tourismusstandorte mit dem öffentlichen Verkehr aus bedeutenden Großstädten Europas. Umweltbundesamt GmbH, Wien, Österreich. Online unter: https:// www.umweltbundesamt.at/fileadmin/site/publikationen/REP0217. pdf (letzter Zugriff. 29.04.2020).

Umweltbundesamt (2013) Anpassungsmaßnahmen der ÖBB-Infrastruktur an den Klimawandel. Umweltbundesamt GmbH, Wien, Österreich. Online unter: http://www5.umweltbundesamt.at/klimawandel/ abfrage/show/4283ebcc-3c0d-1030-89d5-ed5b02f6ce23 (letzter Zugriff: 28.04.2020).

Umweltbundesamt (2014) Anpassungsfahrplan für die österreichische Straßeninfrastruktur. Umweltbundesamt GmbH, Wien, Österreich. Online unter: https://www.umweltbundesamt.at/fileadmin/site/publikationen/REP0495.pdf (letzter Zugriff: 29.04.2020).

Umweltbundesamt (2016) Elfter Umweltkontrollbericht: Umweltsituation in Österreich. Umweltbundesamt $\mathrm{GmbH}$, Wien. Online unter: https://www.umweltbundesamt.at/umweltsituation/umweltkontrollbericht/ukb2016/ (letzter Zugriff: 23.03.2019).

Umweltbundesamt (2018a) Sachstandsbericht Mobilität: mögliche Zielpfade zur Erreichung der Klimaziele 2050 mit dem Zwischenziel 2030. Umweltbundesamt $\mathrm{GmbH}$, Wien, Österreich. Online unter: http://www.umweltbundesamt.at/fileadmin/site/publikationen/ REP0667.pdf (letzter Zugriff: 29.04.2020).

Umweltbundesamt (2018b) Factsheet Treibhausgasbilanz: Urlaubstypen im Vergleich. Im Auftrag der Wirtschaftskammer Österreich (WKO), Fachverband Seilbahnen. Umweltbundesamt GmbH, Wien, Österreich. Online unter: https://www.umweltbundesamt.at/filead$\mathrm{min} /$ site/presse/news_2018/Treibhausgasbilanz_UrlaubsreiseVergleich_Factsheet2018.pdf (letzter Zugriff: 29.04.2020).

Umweltbundesamt (2019) Treibhausgasinventur 2017. Umweltbundesamt GmbH, Wien, Österreich. Online unter: https://www.umweltbundesamt.at/fileadmin/site/presse/news_2019/Hintergrundinformation_THG-Bilanz_2017.pdf (letzter Zugriff: 29.04.2020).

Unger (2018) Die touristische Mobilität - der (fehlende) Schlüssel zur Nachhaltigkeit im Tourismus: das Beispiel Alpbach. Vortrag im Rahmen des Winter Sports Congress 2018an der Fachhochschule Kufstein. Online unter: https://www.fh-kufstein.ac.at/content/download/3536845/file/wintersportscongress_unger_2018\%20kurz_print. pdf (letzter Zugriff: 29.04.2020).

Unger, R., Abegg, B., Mailer, M. \& Stampfl, P. (2016) Energy consumption and greenhouse gas emissions resulting from tourism travel in an Alpine setting. Mountain Research and Development 36(4), 475 483. DOI: https://doi.org/10.1659/MRD-JOURNAL-D-16-00058.1

Verplanken, B., Aarts, H., van Knippenberg, A. \& Knippenberg, C. (1994) Attitude versus general habit: antecedents of travel mode choice. Journal of Applied Social Psychology 24(3), 285-300. DOI: https://doi.org/10.1111/j.1559-1816.1994.tb00583.x

Viadonau (2009) Jahresbericht Donauschiffahrt 2008. Österreichische Wasserstraßen-Gesellschaft mbH, Wien, Österreich. Online unter: http://www.viadonau.org/fileadmin/content/viadonau/01Newsroom/ 
Dokumente/2015/Broschueren/JB_2008_D.pdf (letzter Zugriff: 29.04.2020).

Viadonau (2015) Nationaler Aktionsplan Donauschifffahrt (NAP). Endbericht 2015. Bundesministerium für Verkehr, Innovation und Technologie (BMVIT), Wien, Österreich. Online unter: https://www. bmk.gv.at/themen/wasser/schifffahrt/donau/publikationen/nap.html (letzter Zugriff: 03.06.2020).

Viadonau (2019) Jahresbericht Donauschiffahrt 2018. Österreichische Wasserstraßen-Gesellschaft mbH, Wien, Österreich. Online unter: http://www.viadonau.org/fileadmin/content/viadonau/01Newsroom/ Dokumente/2019/Broschueren/Jahresbericht_2018_dt.pdf (letzter Zugriff: 29.04.2020).

Voll, F. (2014) Erreichbarkeiten im Alpenraum: der Tourismus als Faktor in peripheren Gebieten. In: Bieger, T., Beritelli, P. \& Laesser, C. (Hrsg.) Zukunftsgestaltung im alpinen Tourismus: Schweizer Jahrbuch für Tourismus 2013/2014, S. 89-99. Erich Schmidt Verlag, Berlin, Deutschland.

Wadud, Z. \& Gühnemann, A. (2016) Carbon and noise trading in aviation. In: Agarwal, R., Collier, F., Schäfer, A. \& Seabridge, A. (Hrsg.) Green Aviation, 287-298. John Wiley \& Sons, Chichester, Vereinigtes Königreich.

Wallergraber, M., Holzer, V., Lung, E. \& Frank, B. (2014) Nachhaltige Mobilität im Tourismus: Leitfaden. Bundesministerium für Wissenschaft, Forschung und Wirtschaft (BMWFW), Wien, Österreich. Online unter: https://www.bmk.gv.at/themen/alternative_verkehrskonzepte/tourismus/kooperativ.html (letzter Zugriff: 29.04.2020).

Warnecke, C., Schneider, L., Day, T., La Hoz Theuer, S. \& Fearnehough, H. (2019) Robust eligibility criteria essential for new global scheme to offset aviation emissions. Nature Climate Change 9(3), 218-221. DOI: https://doi.org/10.1038/s41558-019-0415-y

Wietschel, M., Kühnbach, M. \& Rüdiger, D. (2019) Die aktuelle Treibhausgasemissionsbilanz von Elektrofahrzeugen in Deutschland. Fraunhofer-Institut für System- und Innovationsforschung ISI, Karlsruhe, Deutschland. Online unter: https://www.isi.fraunhofer.de/ content/dam/isi/dokumente/sustainability-innovation/2019/WP022019 Treibhausgasemissionsbilanz_von_Fahrzeugen.pdf. (letzter Zugriff: 15.07.2019).

Zech, S., Dangschat, J.S., Dillinger, A., Feilmayr, W., Hauger, G., Kogler, R. \& Vlk, T. (2013) Tourismusmobilität 2030. Bundesministerium für Wirtschaft, Familie und Jugend (BMWFJ), Wien, Österreich. Online unter: https://www.wko.at/branchen/tourismus-freizeitwirtschaft/HP_Tourismusmobilitaet2030_Langfassung_25.11. pdf (letzter Zugriff: 29.04.2020).

Zmud, J., Green, L., Kuhnimhof, T., Le Vine, S., Polak, J. \& Phleps, P. (2017) Still going ... and going: the emerging travel patterns of older adults. Institute for Mobility Research (ifmo), München, Deutschland. Online unter: https://www.bmwgroup.com/content/ dam/grpw/websites/bmwgroup_com/company/downloads/en/2017/ 2017-BMW-Group-IFMO-Publication.September.pdf (letzter Zugriff: 23.07.2019).

Open Access Dieses Buch wird unter der Creative Commons Namensnennung 4.0 International Lizenz (http://creativecommons.org/licenses/by/4.0/deed.de) veröffentlicht, welche die Nutzung, Vervielfältigung, Bearbeitung, Verbreitung und Wiedergabe in jeglichem Medium und Format erlaubt, sofern Sie den/die ursprünglichen Autor(en) und die Quelle ordnungsgemäß nennen, einen Link zur Creative Commons Lizenz beifügen und angeben, ob Änderungen vorgenommen wurden.

Die in diesem Buch enthaltenen Bilder und sonstiges Drittmaterial unterliegen ebenfalls der genannten Creative Commons Lizenz, sofern sich aus der Abbildungslegende nichts anderes ergibt. Sofern das betreffende Material nicht unter der genannten Creative Commons Lizenz steht und die betreffende Handlung nicht nach gesetzlichen Vorschriften erlaubt ist, ist für die oben aufgeführten Weiterverwendungen des Materials die Einwilligung des jeweiligen Rechteinhabers einzuholen.

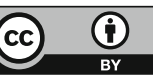

